\title{
Photocatalytic Properties of Tin Oxide and Antimony-Doped Tin Oxide Nanoparticles
}

\author{
J. C. M. Brokken-Zijp, ${ }^{1}$ O. L. J. van Asselen, ${ }^{2}$ W. E. Kleinjan, ${ }^{1}$ R. van de Belt, ${ }^{3}$ and G. de With ${ }^{1}$ \\ ${ }^{1}$ Laboratory of Materials and Interface Chemistry, Eindhoven University of Technology, P.O. Box 513, \\ 5600 MB Eindhoven, The Netherlands \\ ${ }^{2}$ Laboratory of Polymer Technology, Eindhoven University of Technology, P.O. Box 513, 5600 MB Eindhoven, The Netherlands \\ ${ }^{3}$ Research and Development Kriya Materials Group, Kriya Materials B. V., P.O. Box 18, 6160 MD Geleen, The Netherlands \\ Correspondence should be addressed to J. C. M. Brokken-Zijp, j.brokken@tue.nl
}

Received 8 March 2011; Accepted 12 April 2011

Academic Editor: Huisheng Peng

Copyright (๑) 2011 J. C. M. Brokken-Zijp et al. This is an open access article distributed under the Creative Commons Attribution License, which permits unrestricted use, distribution, and reproduction in any medium, provided the original work is properly cited.

For the first time it is shown that $\mathrm{N}$-doped $\mathrm{SnO}_{2}$ nanoparticles photocatalyze directly the polymerization of the $\mathrm{C}=\mathrm{C}$ bonds of (meth)acrylates under visible light illumination. These radical polymerizations also occur when these particles are doped with $\mathrm{Sb}$ and when the surfaces of these particles are grafted with methacrylate (MPS) groups. During irradiation with visible or UV light the position and/or intensity of the plasmon band absorption of these nanoparticles are always changed, suggesting that the polymerization starts by the transfer of an electron from the conduction band of the particle to the (meth)acrylate $\mathrm{C}=\mathrm{C}$ bond. By using illumination wavelengths with a very narrow band width we determined the influence of the incident wavelength of light, the $\mathrm{Sb}$ - and N-doping, and the methacrylate (MPS) surface grafting on the quantum efficiencies for the initiating radical formation $(\Phi)$ and on the polymer and particle network formation. The results are explained by describing the effects of Sb-doping, Ndoping, and/or methacrylate surface grafting on the band gaps, energy level distributions, and surface group reactivities of these nanoparticles. $\mathrm{N}$-doped (MPS grafted) $\mathrm{SnO}_{2}(\mathrm{Sb} \geq 0 \%)$ nanoparticles are new attractive photocatalysts under visible as well as UV illumination.

\section{Introduction}

The photochemistry of semiconductor nanoparticles and nanoparticulate materials is a fast growing area, both in terms of research and commercial activity [1]. These materials are used, for instance, in the treatment of pollutants, for photosterilisation, for photo-induced superhydrophilicity in solar energy to electrical power conversion and photochemical water splitting systems. Also semiconductive nanoparticles/nanostructures can act as a photocatalyst in (meth)acrylate polymerization [2-4]. Most of these applications require a large conversion efficiency under visible (solar) light illumination, but for many of these materials this efficiency is absent, because they absorb only a small fraction of the UV part of the solar spectrum. To enhance the absorption of radiation at higher wavelengths, the influence of doping of these materials is being studied, and considerable improvements in, for instance, the photocatalytic activity of $\mathrm{TiO}_{2}$ for visible light have been reported when these materials were doped with metal ions or nitrogen $[1,5-10]$. Also the incorporation of narrow-band-gab semiconductors or the formation of heterostructures using wide-band-gap semiconductors, such as $\mathrm{ZnO}_{2}-\mathrm{SnO}_{2}$, are promising [11]. However, there is still a strong need for new nanomaterials with a large photocatalytic conversion efficiency for visible (solar) light.

Recently, we showed that $\mathrm{SnO}_{2}$ and Sb-doped $\mathrm{SnO}_{2}$ nanoparticles without the presence of any other photoinitiator can act as photocatalysts for the radical polymerization of (meth)acrylate $\mathrm{C}=\mathrm{C}$ double bonds during illumination with radiation of $315 \pm 5 \mathrm{~nm}$ [12]. The attractiveness of $\mathrm{SnO}_{2}$ and $\mathrm{Sb}$-doped $\mathrm{SnO}_{2}$ materials for these and other photocatalytic applications would be enlarged when they could also act as photocatalysts for UV/vis radiation well above $340 \mathrm{~nm}$, that 
is, using light quanta of which the energy is too small to bridge the band gap of these particles.

Below we report the results of a study on the photocatalytic properties of highly crystalline Sb-doped and/or $\mathrm{N}$-doped $\mathrm{SnO}_{2}$ nanoparticles using radiation of 365,408 , 545 , or $650 \mathrm{~nm}$. This study shows that without the presence of any other photoinitiator these nanoparticles act as photocatalysts for the radical polymerization of $\mathrm{C}=\mathrm{C}$ bonds of (meth)acrylates even when radiation of $650 \mathrm{~nm}$ is used. It will be shown also that the rate of this polymerization and the quantum yield for the formation of the initiating radical depend on the wavelengths of irradiation used, the amount of surface grafting of the nanoparticles with methacrylate groups, and the level of Sb-doping of these particles. The results found will be related to the bulk and surface compositions and properties of these nanoparticles.

Further on we will, for convenience, refer to $\mathrm{SnO}_{2}$ and $\mathrm{Sb}$-doped $\mathrm{SnO}_{2}$ nanoparticles as $\mathrm{Sn}: \mathrm{SbO}_{2}(0 \leq \mathrm{Sb} \leq 13 \%)$ nanoparticles although sometimes this abbreviation is used only for Sb-doped $\mathrm{SnO}_{2}$ particles.

\section{Experimental}

2.1. Chemicals and Materials Used. Polyethyleneglycol diacrylate monomer (PEGDA, $M_{\mathrm{w}}=575 \mathrm{~g} / \mathrm{moL}$ ) was purchased from Aldrich, 3-methacryloxypropyltrimethoxysilane (MPS) from ABCR, and methanol (>99.8\%) from Merck (Scheme 1). Aqueous dispersions of $\mathrm{Sb}: \mathrm{SnO}_{2}$ nanoparticles $(\approx 10 \mathrm{wt} \%)$ with different $\mathrm{Sb}$-doping levels from $\mathrm{Sb} /(\mathrm{Sb}+\mathrm{Sn})$ $=0$ to 13.0 at.\% (after this described as \% Sb) were obtained from Kriya Materials B.V. (Geleen, The Netherlands). The most important data for these spherical particles are shown in Table 1 and Figure 9 [13].

The surface of these $\mathrm{Sb}: \mathrm{SnO}_{2}$ nanoparticles was, in general, modified before use by grafting them with variable amounts of the silane coupling agent 3-methacryloxypropyl trimethoxysilane (MPS) (Schemes 2 and 3) [2, 12, 14]. Sb-doping, N-doping, and $\mathrm{NH}_{3}$ surface groups hardly influenced the amount of grafted MPS and MPS oligomers formed $[12,13]$.

2.2. Preparation of the Starting Dispersions and Formulations. The MPS-Sb:SnO 2 /PEGDA 575 starting mixtures were prepared from the corresponding dispersions of the (MPS-grafted) $\mathrm{Sb}: \mathrm{SnO}_{2}$ nanoparticles by mixing them with PEGDA 575 and methanol. In both dispersions the nanopa rticles were only well dispersed, when the surfaces of these particles were grafted with MPS $[12,13]$. The $\mathrm{Sb}: \mathrm{SnO}_{2}$ particle content was always 10 vol. \%, based on the total amount of PEGDA, $\mathrm{Sb}: \mathrm{SnO}_{2}$, and MPS present. The $\mathrm{MPS} / \mathrm{Sb}: \mathrm{SnO}_{2}$ weight ratio of the mixtures after grafting is different from the initial ratio used in the grafting reaction. For convenience, we use in this paper often the $\mathrm{MPS} / \mathrm{Sb}: \mathrm{SnO}_{2}$ weight ratio before grafting, but the $10 \mathrm{vol} . \%$ particle concentration in the starting dispersion/formulation is based on the corrected MPS/Sb: $\mathrm{SnO}_{2}$ weight ratio after grafting [12].
2.3. Measurement of the Polymerization Rate. Real-time FTIR measurements were performed using a Biorad Excalibur FT-IR spectrometer, equipped with an MCT detector. The spectra were recorded between 650 and $4000 \mathrm{~cm}^{-1}$ using different time intervals between $0.3-30 \mathrm{~s}$ and the kinetic mode of the WinIR-pro software package. An Oriel Spectral Luminator connected to a light guide was used for the illumination of the formulations with wavelengths of 315 , $365,410,545$, or $650 \pm 5 \mathrm{~nm}$. The corresponding incident light intensities used are shown in Table 2.

Grafted MPS, MPS oligomer, and PEGDA 575 contain (meth)acrylate $\mathrm{C}=\mathrm{C}$ bonds. Before the measurements started the (MPS)-Sb: $\mathrm{SnO}_{2} /$ PEGDA 575 dispersion was placed on the diamond crystal of the Golden Gate ATR accessory of our IR apparatus and the solvents were evaporated under a dry $\mathrm{N}_{2}$ flow [12]. After solvent evaporation the layer thickness was adjusted to about $1 \mu \mathrm{m}$. The electronic shutter of the lamp was opened at $t=0$, and the initial and maximum rates of polymerization of the (meth)acrylate $\mathrm{C}=\mathrm{C}$ bonds $\left(R_{\mathrm{ini}}^{\lambda}\right.$, $R_{\max }^{\lambda}$ ) were determined by measuring the initial, respectively, maximum changes in the absorption of the peaks at 1408 , 1620 , and $1637 \mathrm{~cm}^{-1}$ over a certain time period $(\mathrm{C}=\mathrm{C}$ bond absorptions of grafted MPS, MPS oligomer, and/or PEGDA 575). For the determination of the maximum slope of a specific starting formulation at least five different data points were measured. During the whole measurement the shutter of the lamp was left open and the dry nitrogen flow was kept on. The results obtained at 1408 and $1620 \mathrm{~cm}^{-1}$ appeared to be very similar. Hence, only the results measured at 1620 and $1637 \mathrm{~cm}^{-1}$ are shown below.

The measured decreases in absorptions of the $\mathrm{C}=\mathrm{C}$ bonds over time during irradiation were plotted either as an absolute decrease in concentration over time $\left(R_{\mathrm{ini}}^{\lambda}, R_{\max }^{\lambda}\right.$; (1a), (1c)) or as a relative decrease in concentration over time $\left(R_{\mathrm{ini}}^{\lambda}{ }^{m}, R_{\max }^{\lambda}{ }^{m} ;(1 \mathrm{~b}),(1 \mathrm{~d})\right)$. Equations (1b), (1d) were used when reaction rates were compared of starting formulations, which contained different amounts of MPS $\mathrm{C}=\mathrm{C}$ bonds. The concentrations of the $\mathrm{C}=\mathrm{C}$ double bonds $\left[\mathrm{mol} \mathrm{m}^{-3}\right]$ at time $t$ and time $t=0$ are, respectively, $\left(c_{\mathrm{C}=\mathrm{C}}\right)_{t}$ and $\left(c_{\mathrm{C}=\mathrm{C}}\right)_{t=0}$. The standard deviation, $\sqrt{ }\left(\sum\left(x-x_{\mathrm{av}}\right)^{2} /(n-1)\right)$, of $R$ was taken as error margin:

$$
\begin{aligned}
R_{\mathrm{ini}}^{\lambda} & =\left\{c_{(\mathrm{c}=\mathrm{c}) t=0}-c_{(\mathrm{c}=\mathrm{c}) t}\right\} t^{-1}, \\
R_{\mathrm{ini}}^{\lambda{ }^{m}} & =\left\{c_{(\mathrm{c}=\mathrm{c}) t=0}-c_{(\mathrm{c}=\mathrm{c}) t}\right\}\left\{c_{(\mathrm{c}=\mathrm{c}) t=0}\right\}^{-1} t^{-1}, \\
R_{\max }^{\lambda} & =\left\{c_{(\mathrm{c}=\mathrm{c}) t 1}-c_{(\mathrm{c}=\mathrm{c}) t 2}\right\}\left\{t_{2}-t_{1}\right\}^{-1}, \\
R_{\max }^{\lambda \quad m} & =\left\{c_{(\mathrm{c}=\mathrm{c}) t 1}-c_{(\mathrm{c}=\mathrm{c}) t 2}\right\}\left\{c_{(\mathrm{c}=\mathrm{c}) t=0}\right\}^{-1}\left\{t_{2}-t_{1}\right\}^{-1} .
\end{aligned}
$$

Each experiment was repeated at least three times. In general, an S-shaped plot was found when the change in $\mathrm{C}=\mathrm{C}$ bond concentration was plotted against $t$ and always the $R_{\text {ini }}^{\lambda}$ (mol $\left.\mathrm{m}^{-3} \mathrm{~s}^{-1}\right)<R_{\max }^{\lambda}\left(\mathrm{mol} \mathrm{m}^{-3} \mathrm{~s}^{-1}\right)$ and the $R_{\mathrm{ini}}^{\lambda{ }^{m}}\left(\mathrm{~s}^{-1}\right)<R_{\max }^{\lambda}{ }^{m}$ $\left(\mathrm{s}^{-1}\right)$. When no S-shaped plot was found the value for $R_{\text {ini }}^{\lambda}$, $R_{\text {ini }}^{\lambda{ }^{m}}$ was always the largest $R$ value.

When these experiments were performed in the presence of air, $\mathrm{O}_{2}$ became a radical scavenger and the $\mathrm{C}=\mathrm{C}$ polymerization rate slowed down during irradiation. 

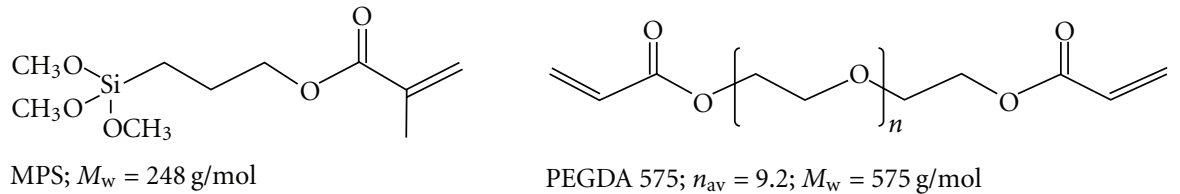

Scheme 1: Molecular formula of 3-metacryloxypropyltrimethoxysilane (MPS) and polyethyleneglycol diacrylate (PEGDA 575).

Table 1: Properties of the $\mathrm{Sb}: \mathrm{SnO}_{2}$ particles used [13].

\begin{tabular}{llllllll}
\hline $\begin{array}{l}\mathrm{Sb} /(\mathrm{Sn}+\mathrm{Sb}) \mathrm{mol} \\
\%(\mathrm{a})\end{array}$ & $\begin{array}{l}\mathrm{Sb}(\mathrm{III}) /[\mathrm{Sb}(\mathrm{III})+\mathrm{Sb}(\mathrm{V})] \\
\mathrm{mol} \%\end{array}$ & $d / \mathrm{nm} \mathrm{BET}^{(\mathrm{c})}$ & $d / \mathrm{nm} \mathrm{XRD}^{(\mathrm{d})}$ & $\begin{array}{l}\mathrm{N}^{(\mathrm{b})} \text { bulk } \\
\text { wt.\% }\end{array}$ & $\begin{array}{l}\mathrm{N}^{(\mathrm{b})} \text { surface } \\
\text { wt.\% }\end{array}$ & $a$ unit cell $\AA$ & $c$ unit cell $\AA$ \\
\hline 0 & 0 & 8.2 & 7.3 & 0.088 & 0.046 & 4.7416 & 3.1808 \\
2.0 & 0 & 7.9 & 6.9 & 0.068 & 0.136 & 4.7432 & 3.1790 \\
7.0 & 7.1 & 6.5 & 0.094 & 0.188 & 4.7509 & 3.1786 \\
13.0 & $0^{(\mathrm{e})}$ & 6.6 & $6.9^{(\mathrm{f})}$ & 0.200 & 0.202 & 4.7435 & 3.1737 \\
\hline
\end{tabular}

(a) Apart from $\mathrm{Sb} 0 \%$ all the $\mathrm{Sb}: \mathrm{SnO}_{2}$ particles are blue powders.

(b) Present in the bulk and at the surface; at the surface as $\mathrm{NH}_{3}$ groups.

(c) The diameter is calculated assuming that the particles were spherical, non-porous with a density of $6.99 \mathrm{~g} / \mathrm{cm}^{3}$.

(d) The particles are (almost) crystalline. The crystallite sizes were calculated from the broadening of the XRD peaks.

(e) No $\mathrm{Sb}$ (III) was detected with XPS; IR data suggest that a very small amount of $\mathrm{Sb}$ (III)-OH surface groups is present.

(f) Measured with TEM: $d=6.3 \pm 1.1 \mathrm{~nm}$.

TABLE 2: Incident light intensities $I_{0}$ at different wavelengths. ${ }^{\text {a }}$

\begin{tabular}{lrrrrr}
\hline$\lambda[\mathrm{nm}]$ & $315 \pm 5$ & $365 \pm 5$ & $410 \pm 5$ & $545 \pm 5$ & $650 \pm 5$ \\
$I_{0}\left[\mathrm{~mW} \mathrm{~cm}^{-2}\right]$ & 0.5 & 1.0 & 1.0 & 1.1 & 0.12 \\
\hline${ }^{a}$ Determined with an Oriel & 70260 Radiant Power Meter.
\end{tabular}

2.4. Measurement of the Light Absorption Spectra of the $\mathrm{Sb}: \mathrm{SnO}_{2} \quad$ Dispersions and XPS Measurements. The light absorption spectra of aqueous $\mathrm{Sb}: \mathrm{SnO}_{2}$ nanoparticle dispersions, in which the $\mathrm{Sb}: \mathrm{SnO}_{2}$ particles were well dispersed, [15] were recorded with a Shimadzu UV 3102 PC Scanning Spectrophotometer, using a rectangular quartz cuvette with a diameter of $1 \mathrm{~cm}$. X-ray photoelectron spectroscopy spectra (XPS) were measured as described before [13].

\section{Results and Discussion}

3.1. Influence of the Wavelength of the Incident Radiation on the Photocatalyzed $C=C$ Polymerization. In an earlier paper the radical polymerization of PEGDA 575 under the influence of $315 \pm 5 \mathrm{~nm}$ irradiation photocatalyzed by MPS-Sb: $\mathrm{SnO}_{2}(\mathrm{Sb} \geq 0)$ nanoparticles was described [12] and the observed photocatalysis was explained as follows: by absorption of light quanta of $315 \mathrm{~nm}$ the electrons in the valence band of the $\mathrm{Sb}: \mathrm{SnO}_{2}$ nanoparticles are excited directly into the conduction band. The activated electron in the conduction band and the hole in the valence band react in the presence of a $\mathrm{C}=\mathrm{C}$ bond and a hydrogen donor under formation of a (meth)acryl radical ( $\mathrm{YH} \cdot$ ). This radical initiates the polymerization of the (meth)acryl $\mathrm{C}=\mathrm{C}$ groups (Scheme 4).

$\mathrm{Sb}: \mathrm{SnO}_{2}(\mathrm{Sb}=0 \%)$ particles/films have a band gap of $3.6 \mathrm{eV}-3.8 \mathrm{eV}$, which corresponds with light quanta of
320-340 nm [16, 17]. Hence, when MPS-Sb: $\mathrm{SnO}_{2}$ (Sb $=0 \%) /$ PEGDA 575 formulations without any other photocatalytic molecule/particle are irradiated with light with wavelengths well above $340 \mathrm{~nm}$ a direct excitation of the electron from the valence band into the conduction band can no longer occur $[8,17]$. Still very similar changes in the IR spectra of the formulations are observed during irradiation with $365,408,545$, or $650 \pm 5 \mathrm{~nm}$ to those when these formulations were irradiated with $315 \mathrm{~nm}$ (Figure 1(a)). These changes are also found when the nanoparticles are doped with Sb (Figure 1) [12, 18].

Using the same starting formulations, but without $\mathrm{Sb}: \mathrm{SnO}_{2}$ particles or any other photoinitiator, a change in the IR spectra during irradiation with light $\geq 365 \mathrm{~nm}$ is no longer observed. Hence, MPS-Sb: $\mathrm{SnO}_{2}$ nanoparticles $(\mathrm{Sb} \geq 0 \%)$ photocatalyze the radical polymerization of the (meth)acrylate $\mathrm{C}=\mathrm{C}$ bonds according to the mechanism proposed in Scheme 4 even when the energy of the light quanta is (far) too small to transfer an electron from the valence band into the conduction band of these nanoparticles.

During irradiation the $\mathrm{C}=\mathrm{C}$ bonds in the IR spectra at $1637,1620,1408,986,814$, and $810 \mathrm{~cm}^{-1}$ disappear [12]. At $1637 \mathrm{~cm}^{-1}$ the methacrylate MPS $\mathrm{C}=\mathrm{C}$ and the acrylate $\mathrm{C}=\mathrm{C}$ bonds absorb IR radiation, whereas at 1620 and $1408 \mathrm{~cm}^{-1}$ only the acrylate $\mathrm{C}=\mathrm{C}$ bonds absorb [18]. Hence, the methacrylate as well as the acrylate $\mathrm{C}=\mathrm{C}$ bonds polymerizes during irradiation (see also later on).

The energy of the light quanta of wavelengths $\geq 365 \mathrm{~nm}$ is (far) too small to transfer an electron from the valence band directly into the conduction band. Hence, energy levels in the band gab of the $\mathrm{Sb}: \mathrm{SnO}_{2}$ nanoparticles are likely to be involved in the initiation of the radical polymerization. Our $\mathrm{Sb}: \mathrm{SnO}_{2}$ particles $(\mathrm{Sb}=0 \%)$ are always doped with $\mathrm{N}$ and these particles, contrary to what was reported before for 
OH
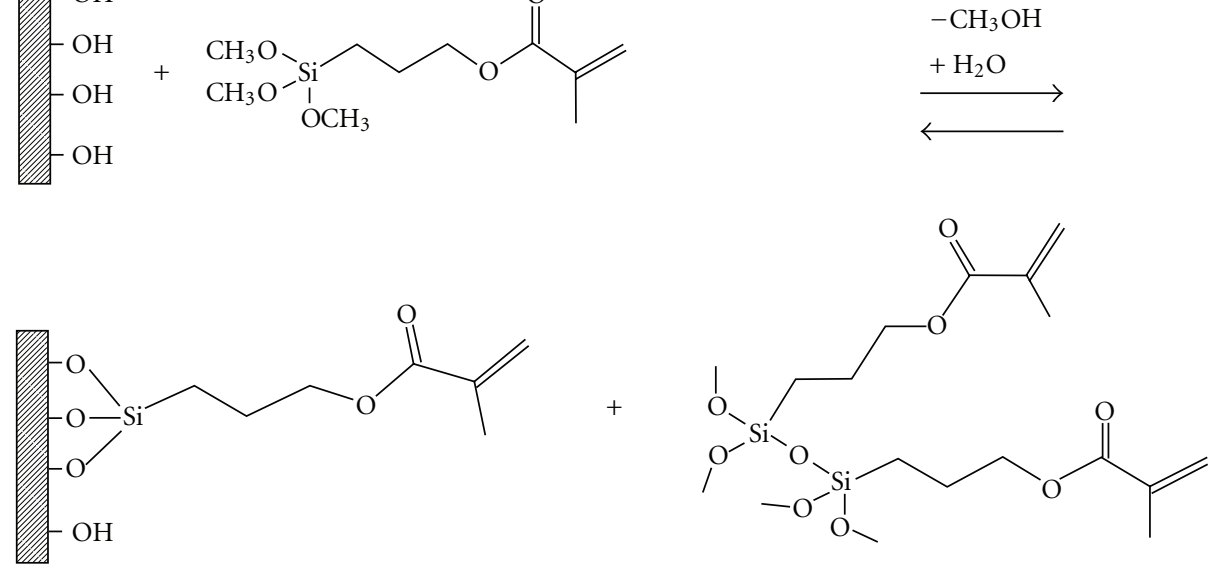

Scheme 2: Schematic presentation of grafting of 3-metacryloxypropyltrimethoxysilane (MPS) to OH-groups of the $\mathrm{Sb}: \mathrm{SnO}_{2}$ particle surface and formation of MPS oligomers.

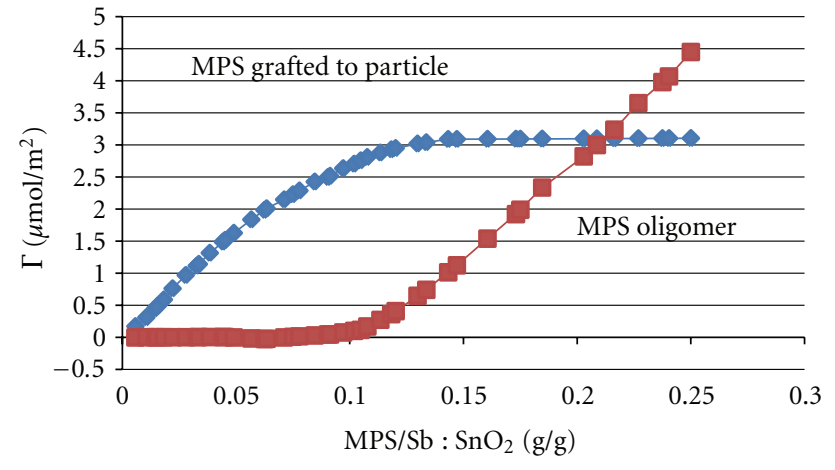

Scheme 3: Amount of MPS grafted on the surface of the $\mathrm{Sb}: \mathrm{SnO}_{2}$ nanoparticles surface and amount of MPS oligomer formed as a function of initial MPS/Sb: $\mathrm{SnO}_{2}$ ratios used in the grafting reaction [12].

non-doped $\mathrm{SnO}_{2}$, absorb visible light (Table 1, Figure 2) [12, 13]. This suggests that these levels in the band gap are formed by $\mathrm{N}$-doping. This is confirmed by a recent publication that shows that $\mathrm{N}$-doped $\mathrm{SnO}_{2}$ films can photocatalyze the oxidation of methylene blue under visible light illumination $[19,20]$.

During illumination of the MPS-Sb: $\mathrm{SnO}_{2}(\mathrm{Sb}=0 \%) /$ PEGDA 575 mixture with 315, 365, 408, 545, or $650 \mathrm{~nm}$, always an increase in absorption and shift in intensity of the plasmon band of the particles are observed in the IR spectra (Figure 3). The plasmon band absorption is due to the reflection of the electric field of the incident IR light by the combined oscillations of the electrons in the conduction band of the $\mathrm{Sb}: \mathrm{SnO}_{2}$ particles [21-23]. These observed changes show that electrons are also transferred into the conduction band of our particles during irradiation with light of wavelengths $\geq 365 \mathrm{~nm}$ [24]. Hence, the occurrence of these photocatalyzed polymerizations may be explained by band gap narrowing through $\mathrm{N}$-doping and/or by the involvement of $\mathrm{N}$-related energy levels of these nanoparticles in the transfer of an electron into the conduction band (see also later on).

The (MPS)-Sb: $\mathrm{SnO}_{2}$ particles $(\mathrm{Sb}>0 \%)$ are also doped with $\mathrm{N}$, and these particles also absorb visible light (Table 1, Figure 2) [12, 13]. Similar changes in the plasmon absorption band of their PEGDA formulations are found during irradiation with $315,365,408,545$, or $650 \mathrm{~nm}$ in the IR spectra of their PEGDA formulations (Figure 3) [21-23]. Hence, the same conclusions can be drawn. During irradiation electrons are transferred into the conduction band and an activated electron initiates the $\mathrm{C}=\mathrm{C}$ bond polymerization (Scheme 4 ). That these reactions occur even when the energy of the light quanta is well below $3.4 \mathrm{eV}$ may be explained by band gap narrowing through $\mathrm{N}$-doping and/or by the involvement of $\mathrm{N}$-related energy levels of these nanoparticles in the transfer of an electron into the conduction band.

Especially at high Sb-doping levels the plasmon band may absorb also radiation at wavelengths $<1200 \mathrm{~nm}$. Hence, a small part of the measured absorptions at 545 and $650 \mathrm{~nm}$ in Figure 2 may be actually contributed to this plasmon band. Lack of information in the literature and limitations of our equipment made it impossible to determine the contribution of the plasmon band to the absorption below $1200 \mathrm{~nm}$, and therefore we neglect this aspect in the discussion below.

\subsection{Quantum Yields at Different Wavelengths of Irradiation.}

It is well known that the rate of a reaction which is photocatalyzed by a semiconductive inorganic particle/layer depends on the surface area and crystallinity of these activators [5]. Hence, in this work well-characterized $\mathrm{Sb}: \mathrm{SnO}_{2}$ nanoparticles of varying composition, but with similar nanoparticle sizes and crystallinities, are used (Table 1). To be certain that these particles are well dispersed before and during irradiation in the acrylate monomer their surfaces were grafted in advance with MPS [13, 14, 25]. PEGDA 575 was chosen as acrylate monomer to minimize the influence of viscosity variations on the rate of the acrylate polymerization during irradiation. 


\begin{tabular}{|c|c|c|}
\hline $\begin{array}{l}\text { (MPS)-Sb:SnO }{ }_{2}+h v \\
\mathrm{e}_{\mathrm{CB}^{-}}+\mathrm{h}_{\mathrm{VB}^{+}}\end{array}$ & $\longrightarrow \mathrm{e}_{\mathrm{CB}^{-}}+\mathrm{h}_{\mathrm{VB}^{+}}$ & $\begin{array}{l}\text { light absorption } \\
\text { heat }\end{array}$ \\
\hline $\mathrm{e}_{\mathrm{CB}^{-}}+\mathrm{h}_{\mathrm{VB}^{+}}+\mathrm{H}-\mathrm{X}+\mathrm{Y}$ & $\rightarrow \mathrm{YH} \cdot+\mathrm{X}$. & formation ofi nitiating radical \\
\hline $\mathrm{YH} \cdot+(m+1) \mathrm{Y}$ & $\longrightarrow \mathrm{HY}-(\mathrm{Y})_{m}-\mathrm{Y}$ & polymerization propagation step \\
\hline $\begin{array}{l}2 \mathrm{HY}-(\mathrm{Y})_{n}-\mathrm{Y} \\
2 \mathrm{X}\end{array}$ & $\begin{array}{l}\longrightarrow \mathrm{HY}-(\mathrm{Y})_{2 n+2}-\mathrm{YH} \\
\longrightarrow \mathrm{X}_{2}\end{array}$ & $\begin{array}{l}\text { polymerization termination step } \\
\text { termination step }\end{array}$ \\
\hline
\end{tabular}

Scheme 4: The photocatalytic radical polymerization of (meth)acrylate $\mathrm{C}=\mathrm{C}$ bonds initiated by the $\mathrm{Sb}: \mathrm{SnO}_{2} \mathrm{particles}$. (MPS)-Sb:SnO 2 means the $\mathrm{Sb}: \mathrm{SnO}_{2}$ particles grafted or not grafted with MPS; Y is PEGDA 575 monomer, grafted MPS, and/or MPS oligomer (Scheme 2). $\mathrm{H}-\mathrm{X}$ is a hydrogen donor.

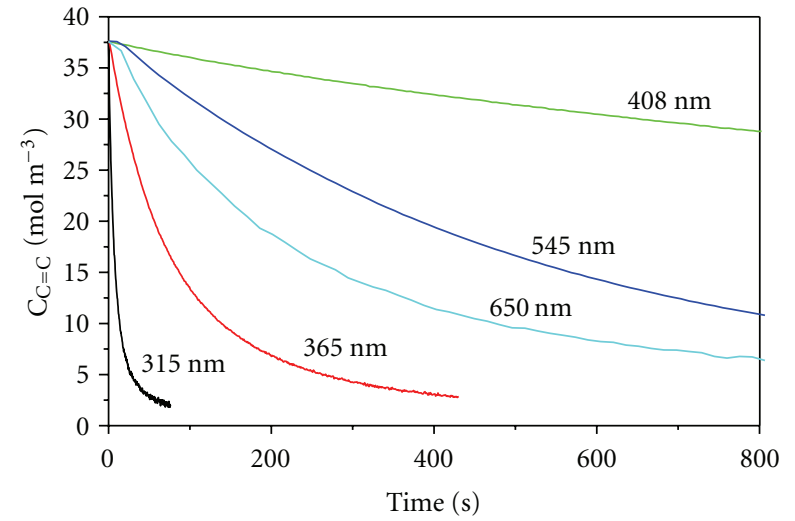

(a)

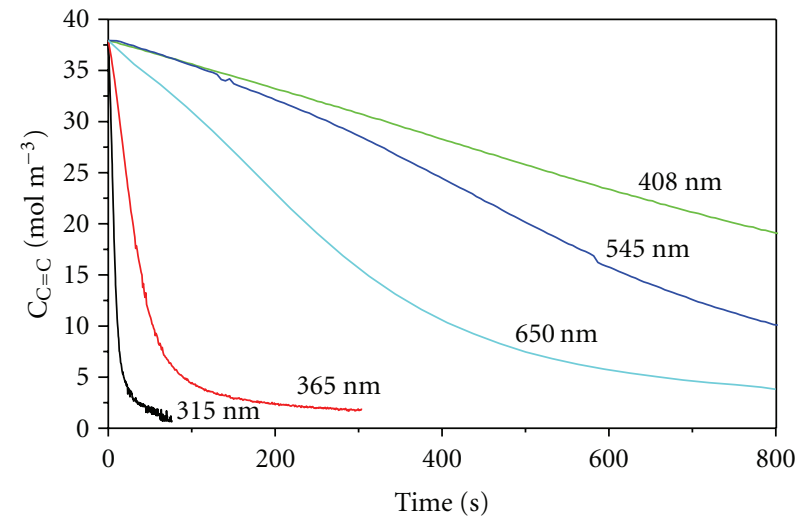

(b)

FIGURE 1: The decreases in the $\mathrm{C}=\mathrm{C}$ bond concentration over time (at $1637 \mathrm{~cm}^{-1}$ ) during irradiation of MPS-Sb : $\mathrm{SnO} 2 / \mathrm{PEGDA}$ formulations using incident light of 315, 365, 408, 545, or $650 \pm 5 \mathrm{~nm}$. MPS $/ \mathrm{Sb}: \mathrm{SnO}_{2}=0.19 \mathrm{~g} / \mathrm{g}$; $c_{\text {particle }}=10 \mathrm{vol} \%$. (a) $\mathrm{Sb}=0 \%$; (b) $\mathrm{Sb}=7 \%$.

To determine the rates of the photocatalyzed polymerizations of the (meth)acrylate $\mathrm{C}=\mathrm{C}$ bonds during irradiation with $315,365,408,545$, or $650 \pm 5 \mathrm{~nm}$ we used real-time FT-IR spectroscopy (Figure 1). For MPS-Sb : $\mathrm{SnO}_{2}(\mathrm{Sb} \geq 2 \%$ ) nanoparticle/PEGDA mixtures always an $\mathrm{S}$-shape relation was found between the decrease in $\mathrm{C}=\mathrm{C}$ bond concentration and irradiation time (Figure 1). Hence, for these particles the initial rate of polymerization $R_{\text {ini }}^{\lambda}$ appears to be always lower than the maximum rate of polymerization $R_{\max }^{\lambda}$, and therefore both were determined independently using (1a)(4) (Scheme 4):

$$
\begin{aligned}
R_{\mathrm{ini}}^{\lambda}= & K_{\mathrm{ini}}^{\lambda}\left\{c_{(\mathrm{c}=\mathrm{c}) t=0}-c_{(\mathrm{c}=\mathrm{c}) t}\right\} \\
& \times\left\{I_{0}\left(1-10^{-\varepsilon \cdot c_{\text {particle }} \cdot d}\right) d^{-1}\right\}^{1 / 2}, \\
R_{\max }^{\lambda}= & K_{\max }^{\lambda}\left\{c_{(\mathrm{c}=\mathrm{c}) t 1}-c_{(c=c) t 2}\right\} \\
& \times\left\{I_{0}\left(1-10^{-\varepsilon \cdot c_{\text {particle }} \cdot d}\right) d^{-1}\right\}^{1 / 2}, \\
K_{\mathrm{ini} / \max }^{\lambda}= & k_{p(\text { ini } / \max )}^{\lambda}\left\{\Phi\left(k_{t(\text { ini/max })}^{\lambda}\right)^{-1}\right\}^{1 / 2} .
\end{aligned}
$$

In these relations the $\left(\mathcal{c}_{\mathrm{c}=\mathrm{c}}\right)_{t=0}\left[\mathrm{~mol} \mathrm{~m}^{-3}\right]$ is the initial concentration of the $\mathrm{C}=\mathrm{C}$ bonds just before the irradiation starts and the $C_{(\mathrm{c}=\mathrm{c}) t}\left[\mathrm{~mol} \mathrm{~m}^{-3}\right]$ is the $\mathrm{C}=\mathrm{C}$ bond concentration at time $t[\mathrm{~s}]$. The rate $R_{\mathrm{ini} / \max }^{\lambda}\left[\mathrm{mol} \mathrm{m}^{-3} \mathrm{~s}^{-3}\right]$ is a function of the propagating $\left(k_{p}\right)$ and terminating polymerization rate constants $k_{t}\left[\mathrm{~m}^{3} \mathrm{~mol}^{-1} \mathrm{~s}^{-1}\right]$, the quantum yield for the formation of the initiating radical $\Phi\left[\mathrm{mol} \mathrm{J}^{-1}\right]$, the incident radiation intensity $I_{0}\left[\mathrm{~J} \mathrm{~m}^{-2} \mathrm{~s}^{-1}\right]$, the $\varepsilon$ of the absorbing $\mathrm{Sb}: \mathrm{SnO}_{2}$ particles at a certain wavelength, the $\mathrm{Sb}: \mathrm{SnO}_{2}$ particle concentration $c_{\text {particle }}\left[\mathrm{mol} \mathrm{m}^{-3}\right]$, the thickness of the irradiated film $d[\mathrm{~m}]$, and the relative quantum efficiency at the initial stage of the reaction $\left(K_{\mathrm{ini}}^{\lambda} ; \mathrm{m}^{3 / 2} \mathrm{~s}^{-1 / 2} \mathrm{~J}^{-1 / 2}\right)$ or at the maximum rate of the reaction $\left(K_{\max }^{\lambda} ; \mathrm{m}^{3 / 2} \mathrm{~s}^{-1 / 2} \mathrm{~J}^{-1 / 2}\right)$. A similar approach was used for the determination of the polymerization rates of (meth)acrylate $\mathrm{C}=\mathrm{C}$ bonds photocatalyzed by an organic photoinitiator or inorganic particle $[2,3,12,26-28]$.

Recently, we showed that the polymerizations of the (meth)acrylate $\mathrm{C}=\mathrm{C}$ bonds photocatalyzed by MPS$\mathrm{Sb}: \mathrm{SnO}_{2}(\mathrm{Sb} \geq 0 \%)$ nanoparticles using radiation of $315 \mathrm{~nm}$ can be explained by (1a)-(4). To test whether these equations also explain our results for illuminations with wavelengths of light above $340 \mathrm{~nm}$, experiments with $365 \mathrm{~nm}$ were done with two different light intensities, one nine times lower than the other using for both the same starting MPS-Sb:SnO $2 /$ PEGDA dispersion. The ratio of these $R_{\max }{ }^{1637}$ values appeared to be 3 , in agreement with the proportionality of $\sqrt{ } I_{0}$ of (3).

From the decrease in the $\mathrm{C}=\mathrm{C}$ bond absorptions at 1637 or $1620 \mathrm{~cm}^{-1}$ over time, the initial and maximum relative quantum efficiencies $K$ are calculated (for $\mathrm{Sb}=7 \%$ initial and 


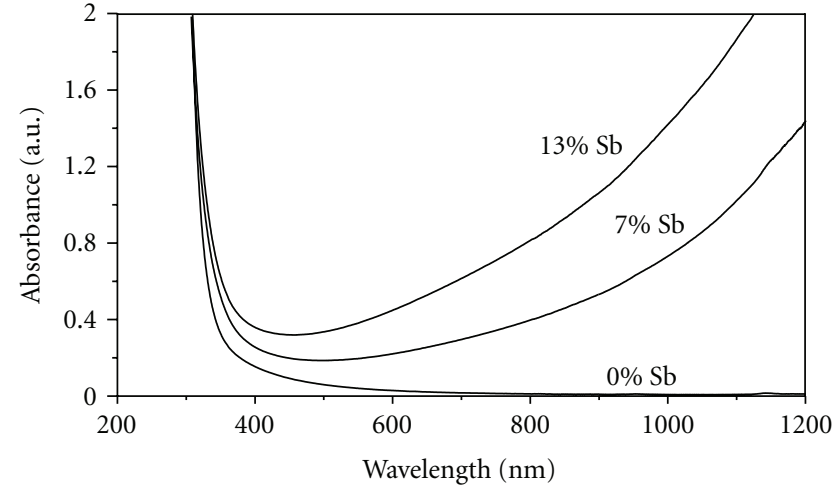

(a)

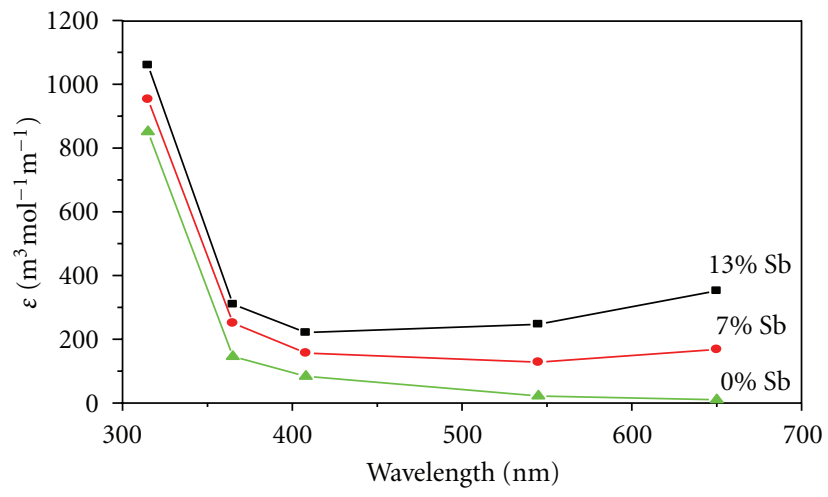

(b)

FigURE 2: (a) UV/Vis absorbance spectra of $\mathrm{Sb}: \mathrm{SnO}_{2}$ nanoparticles in aqueous dispersion. The $\mathrm{Sb}: \mathrm{SnO}_{2}$ particle concentration is 0.23 wt $\%$. (b) Molar extinction coefficients, $\varepsilon$, of $\mathrm{Sb}: \mathrm{SnO}_{2}$ nanoparticles as a function of wavelength for different Sb-doping levels, determined from (a).
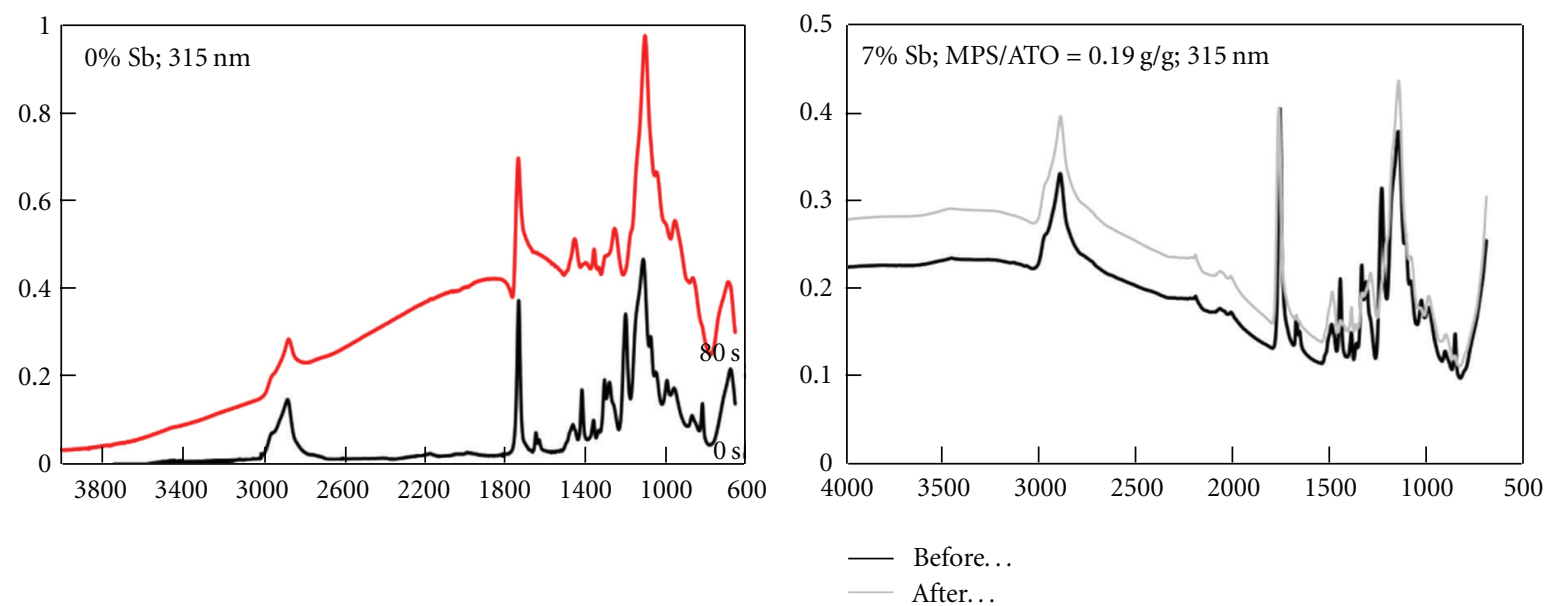

(a)
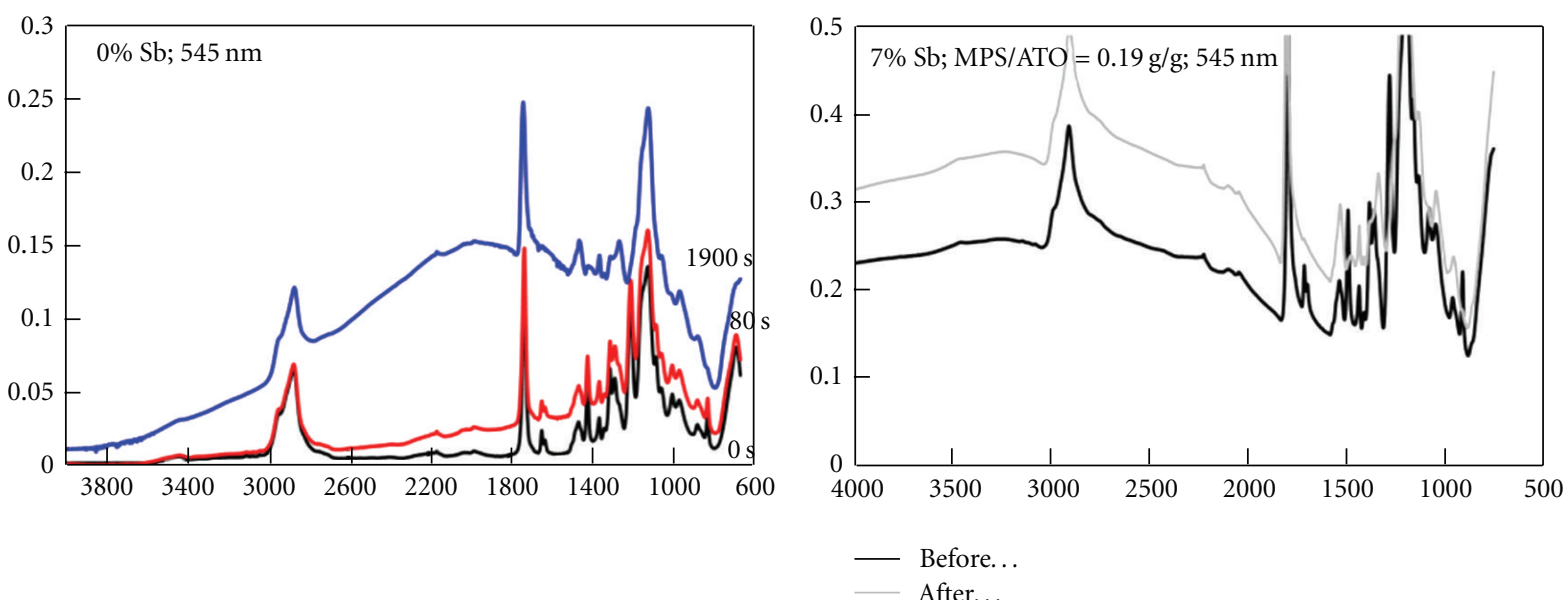

(c)

(d)

FIGURE 3: Infrared absorption spectra before and during irradiation of $\mathrm{Sb}: \mathrm{SnO}_{2}(\mathrm{Sb} \geq 0 \%) / \mathrm{PEGDA} 575$ formulations $(\mathrm{Sb}=0 \%$ or $\mathrm{Sb}=7 \%)$. $\mathrm{MPS} / \mathrm{Sb}: \mathrm{SnO}_{2}=0.19 \mathrm{~g} / \mathrm{g}$. Incident wavelength of radiation: 315 or $545 \mathrm{~nm}$. The results obtained fusing incident radiation of 365 , 408 or $650 \mathrm{~nm}$ are similar. 
maximum; for $\mathrm{Sb}=0 \%$ only initial) (Table 3 ). Because the incident radiation intensities used were sometimes different, the measured $R$ and calculated $K$ values were also corrected for these differences using (2) and (3) $\left(R^{*}, K^{*}\right)$. Table 3 and Figure 4 show that the $K^{*}$ values depend on the incident wavelength of light used. The $\mathrm{C}=\mathrm{C}$ acrylate bonds of the monomer (PEGDA 575) absorb at 1637 and $1620 \mathrm{~cm}^{-1}$ and methacrylate $\mathrm{C}=\mathrm{C}$ bonds (grafted MPS and MPS oligomer) absorb at $1637 \mathrm{~cm}^{-1}$ [18]. A comparison made between the rates measured at these wavenumbers will give more insight into the polymer networks formed.

First the discussion is focused on the MPS-Sb: $\mathrm{SnO}_{2}$ nanoparticles doped with Sb 7\% (Figure 4(b); Tables 3(a) and 3(b)). For these particles the measured $R_{\max }^{*}{ }^{1637}$ values for radiation of $365,408,545$, and $650 \mathrm{~nm}$ are within the experimental error equal to the $R_{\max }^{*}{ }^{1620}$. Hence, at this moment in time the propagation step of the $\mathrm{C}=\mathrm{C}$ bond polymerization at time $t=t_{\max }$ can be described as the reaction between a polymer fragment with an acrylate end group radical and an acrylate monomer. This means that the differences found in the relative quantum yield $K_{\max }^{*}{ }^{1637}$ for the different incident light wavelengths in Table $3 \mathrm{~b}$ are caused by a difference in the quantum yield $\Phi_{\mathrm{Sb}-7 \%}$ for the formation of the initiating radical (4).

For the $\mathrm{Sb}=7 \%$ particles the value of $K_{\mathrm{ini}}^{* 1620}$ is always about $40 \%$ lower than the $K_{\text {ini }}^{* 1637}$ value (Tables 3(a), 3(b) and Figure $4 \mathrm{~b}$ ). These lower values were also reported earlier for similar formulations when radiation of $315 \mathrm{~nm}$ was used and can be explained by the large preference of a methacrylate radical end group to react with a methacrylate $\mathrm{C}=\mathrm{C}$ double bond [12]. This phenomenon is well known for radical initiated polymerizations of mixtures of acrylate and methacrylate $\mathrm{C}=\mathrm{C}$ bonds $[12,14,29]$. Hence, the $\mathrm{C}=\mathrm{C}$ propagation step at the initial part of the polymerization reaction can be partly described as a reaction between a polymer fragment with a methacrylate radical end group and a methacrylate MPS $\mathrm{C}=\mathrm{C}$ bond. Moreover, the ratios of $K_{\mathrm{ini}}^{* 1637}$ and $K_{\max }^{*}{ }^{1637}$ and the ratios of $K_{\mathrm{ini}}^{* 1637}$ and $K_{\mathrm{ini}}^{* 1620}$ are similar for the different wavelengths of radiation used (Table 3). This confirms that the dependency of $K_{\mathrm{ini}}^{*}$ and $K_{\max }^{*}$ on the incident wavelength of radiation is mainly caused by the dependency of the quantum yield $\Phi_{\mathrm{Sb} 7 \%}$ on this wavelength and that the lowering of $K_{\mathrm{ini}}^{* 1637}$ and of $K_{\mathrm{ini}}^{*}{ }^{1620}$ with respect to $K_{\max }^{*}{ }^{1637}$ is caused by the preference of the methacryl radical end group to react with a methacryl double bond or, in other words, by a decrease in the contribution of $k_{p} k_{t}^{-1 / 2}$ to $K_{\text {ini }}^{*}(4)$.

For $\mathrm{Sb}: \mathrm{SnO}_{2}$ particles without $\mathrm{Sb}$-doping no S-shape relation between the decrease in the $\mathrm{C}=\mathrm{C}$ bond absorption and irradiation time is found and the rate at the initial stage of the reaction is the largest rate measured. For convenience we still call these rates initial.

As has been discussed before acrylate $\mathrm{C}=\mathrm{C}$ bonds absorb at 1620 and $1637 \mathrm{~cm}^{-1}$, whereas methacrylate $\mathrm{C}=\mathrm{C}$ bonds absorb only at $1637 \mathrm{~cm}^{-1}$ [18]. The methacrylate $\mathrm{C}=\mathrm{C}$ bond concentration is about $10 \%$ of the acrylate $\mathrm{C}=\mathrm{C}$ bond concentration in the starting formulations of Table 3 [12]. Still for formulations containing particles without Sb-doping the value of $K_{\text {ini }}^{* 1620}$ is about $45 \%$ lower than $K_{\text {ini }}^{*}{ }^{1637}$ (Table 3(c), Figure 4(a)). Hence, for these formulations too, the propagation step at the initial part of the polymerization reaction is mainly a reaction between a polymer fragment with a methacrylate radical end group and a methacrylate $\mathrm{C}=\mathrm{C}$ bond, and the differences in these two $K^{*}$ values for each wavelength of irradiation can be explained by the differences in $k_{\mathrm{p}} k_{t}^{-1 / 2}$ for methacrylates versus acrylates $\mathrm{C}=\mathrm{C}$ bonds.

Table 3(c) also shows that the $K_{\mathrm{ini}}^{*}{ }^{1637} / K_{\mathrm{ini}}^{*}{ }^{1620}$ ratios for particles without Sb-doping are very similar and independent of the wavelength of irradiation used. This suggests that the large variations reported for $K_{\mathrm{ini}}^{*}{ }^{1637}$ in this table can be explained also by a strong dependency of $\Phi_{\mathrm{Sb}-0 \%}$ on the incident radiation wavelength used. The $K_{\mathrm{ini}}^{*}{ }^{1637}$ values are always larger when particles without Sb-doping are used in respect to the $K_{\mathrm{ini}}^{* 1637}$ values for particles with Sb-doping of $7 \%$. This can be explained by a strong influence of Sb-doping on $\Phi\left(\Phi_{\mathrm{Sb}-0 \%}>\Phi_{\mathrm{Sb}-7 \%}\right)$ (Figure 4$)$.

When we compare the results of the particles with $\mathrm{Sb}=$ $0 \%$ and $\mathrm{Sb}=7 \%$ it is important to realize that the surfaces of both particles are grafted with a monolayer MPS and the amount of MPS oligomer present in both dispersions is very similar (Scheme 3 ). Moreover, these particles have a similar crystallinity, they are well dispersed in the starting formulation, and their surface areas in contact with the liquid is similar too (Table 1). Hence, the differences in MPS grafting, MPS oligomer concentration, particle crystallinity, and surface areas between these particles are small and cannot explain that the $K_{\mathrm{ini}}^{* 1637}$ and $K_{\mathrm{ini}}^{* 1620}$ values are always larger for particles with $\mathrm{Sb}=0 \%$ than for particles with $\mathrm{Sb}$ $=7 \%$ (Figure 4 ). These differences can be explained by a strong influence of Sb-doping on $\Phi\left(\Phi_{\mathrm{Sb}-0 \%}>\Phi_{\mathrm{Sb}-7 \%}\right)$ and suggest a more efficient formation of YH radicals (Scheme 1) for particles with $\mathrm{Sb}=0 \%$. We cannot directly measure for particle formulations with $\mathrm{Sb}=0 \%$ the rates of the reactions between a polymer fragment with an acrylate end group and an acrylate $\mathrm{C}=\mathrm{C}$ bond, but we can estimate the corresponding $K_{\max }^{*}{ }^{1637}$ values $\left(K_{\max }^{*}{ }^{1637}\right)_{\text {corr }}$ using the corresponding $k_{p} k_{\mathrm{t}}^{-1 / 2}$ values of particles with $\mathrm{Sb}=7 \%$ (Figure $4(\mathrm{a}))$. The $\left(K_{\max }^{*}{ }^{1637}\right)_{\text {corr }}$ confirms that $\Phi$ is also dependent on Sb-doping.

When the $\mathrm{Sb}: \mathrm{SnO}_{2}$ particles are not doped with $\mathrm{Sb}$, deep impurity (donor) energy levels, which are efficient hole scavengers, are likely to be present in the crystals [30, 31]. The much higher $\Phi_{\mathrm{Sb}-0 \%}$ than $\Phi_{\mathrm{Sb}-7 \%}$ may be explained also by the presence of these energy levels (for more details see below).

\subsubsection{Influence of MPS Grafting and MPS Oligomers.} $\mathrm{Sb}: \mathrm{SnO}_{2}$ nanoparticles can be kept well dispersed over a longer period of time in acrylate monomer dispersions when the surfaces of these particles are grafted with MPS before adding them to the PEGDA monomer. Without this surface modification the particles in the acrylate monomer agglomerate before, during, and after processing $[2,12,15$, 22 ] and this agglomeration becomes visible by the naked eye during irradiation in our experiments. This agglomeration influences the surface area of the particles in contact with the 
TAble 3: (a) $\mathbf{R}_{\max }{ }^{1637}, \mathbf{R}_{\max }^{*}{ }^{1637}, \mathbf{K}_{\max }^{*}{ }^{1637}$, and $\Phi_{\lambda} / \Phi_{315}$ measured at $1637 \mathrm{~cm}^{-1}$ using different wavelengths of irradiation $(\lambda)$. Sb doping: $7 \%$. ${ }^{\text {a,b }}$ (b) $\mathbf{R}_{\text {ini }}^{*}, \mathbf{K}_{\text {ini }}^{*}, \mathbf{K}_{\text {ini }}^{*} / \mathbf{K}_{\max }^{*}$ and $\mathbf{K}_{\text {ini }}^{*} / \mathbf{K}_{\text {ini }}^{*}$ measured at $1637 \mathrm{~cm}^{-1}$, and $1620 \mathrm{~cm}^{-1}$ using different wavelengths of irradiation $(\lambda)$. Sb doping: $7 \%$.,b (c) $\mathbf{R}_{\mathrm{ini}}^{*}$ and $\mathbf{K}_{\mathrm{ini}}^{*}$ measured at $1637 \mathrm{~cm}^{-1}$ and $1620 \mathrm{~cm}^{-1}$ different wavelengths of irradiation $(\lambda)$. Sb doping: $0 \%$. ${ }^{\mathrm{a}} \mathrm{b}$

(a)

\begin{tabular}{lcccc}
\hline$\lambda[\mathrm{nm}]$ & $R_{\max }{ }^{1637}\left[\mathrm{~mol} \mathrm{~m}^{-3} \mathrm{~s}^{-1}\right]$ & $R_{\max }^{*}{ }^{1637}\left[\mathrm{~mol} \mathrm{~m}^{-3} \mathrm{~s}^{-1}\right]$ & $K_{\max }^{*}{ }^{1637}\left[\mathrm{~m}^{3 / 2} \mathrm{~s}^{-1 / 2} \mathrm{~J}^{-1 / 2}\right]$ & $3 \times 10^{-4}$ \\
\hline 315 & 3.0 & 4.2 & $1 \times 10^{-4}$ & 0.4 \\
365 & 0.65 & 0.65 & $0.04 \times 10^{-4}$ & 0.01 \\
408 & 0.025 & 0.025 & $0.07 \times 10^{-4}$ & 0.02 \\
545 & 0.035 & 0.033 & $1 \times 10^{-4}$ \\
650 & 0.081 & 0.23 & 0.3 \\
\hline
\end{tabular}

${ }^{\mathrm{a}} \mathrm{MPS} / \mathrm{Sb}: \mathrm{SnO}_{2}=0.19 \mathrm{~g} / \mathrm{g} ; c_{\text {particle }}=10 \mathrm{vol} . \%$.

${ }^{\mathrm{b}} R_{\max }^{*}{ }^{1637}$ values are $R_{\max }^{*}{ }^{1637}$ values corrected for differences in $I_{0}$, and these $R_{\max }^{*}{ }^{1637}$ values are within experimental error equal to $R_{\max }^{*}{ }^{1620}$. The $K_{\max }^{*}{ }^{1637}$ values were calculated from the $R_{\max }^{*}{ }^{1637}$ values.

(b)

\begin{tabular}{lllllll}
\hline$\lambda[\mathrm{nm}]$ & $\begin{array}{l}R_{\mathrm{ini}}^{* 1637}[\mathrm{~mol} \\
\left.\mathrm{m}^{-3} \mathrm{~s}^{-1}\right]\end{array}$ & $\begin{array}{l}R_{\mathrm{ini}}^{* 1620}[\mathrm{~mol} \\
\left.\mathrm{m}^{-3} \mathrm{~s}^{-1}\right]\end{array}$ & $\begin{array}{l}K_{\mathrm{ini}}^{* 1637}\left[\mathrm{~m}^{3 / 2}\right. \\
\left.\mathrm{s}^{-1 / 2} \mathrm{~J}^{-1 / 2}\right]\end{array}$ & $\begin{array}{l}K_{\mathrm{ini}}^{* 1620}\left[\mathrm{~m}^{3 / 2}\right. \\
\left.\mathrm{s}^{-1 / 2} \mathrm{~J}^{-1 / 2}\right]\end{array}$ & $K_{\mathrm{ini}}^{* 1637} / K_{\mathrm{max}}^{*}{ }^{1637}$ & $K_{\mathrm{ini}}^{* 1637} / K_{\mathrm{ini}}^{* 1620}$ \\
\hline 315 & 2.58 & 1.50 & $2.0 \times 10^{-4}$ & $1.0 \times 10^{-4}$ & 0.5 & 1.5 \\
365 & 0.47 & 0.39 & $0.5 \times 10^{-4}$ & $0.3 \times 10^{-4}$ & 0.6 & 1.5 \\
545 & 0.023 & 0.015 & $0.03 \times 10^{-4}$ & $0.02 \times 10^{-4}$ & 0.7 & 1.5 \\
650 & 0.023 & 0.015 & $0.04 \times 10^{-4}$ & $0.03 \times 10^{-4}$ & 0.6 & 1.3 \\
\hline
\end{tabular}

${ }^{\mathrm{a}} \mathrm{MPS} / \mathrm{Sb}: \mathrm{SnO}_{2}=0.19 \mathrm{~g} / \mathrm{g} ; c_{\text {particle }}=10 \mathrm{vol} \%$.

${ }^{\mathrm{b}}$ The $K_{\max }{ }^{1637}$ values used are shown in Table $3(\mathrm{a})$. The $K_{\mathrm{ini}}^{*}$ corrected for differences in $I_{0}$. The values $K_{\text {ini }}^{*}$ were calculated from the corresponding $R_{\mathrm{ini}}^{*}$ values.

(c)

\begin{tabular}{lccccc}
\hline$\lambda[\mathrm{nm}]$ & $R_{\mathrm{ini}}^{* 1637}\left[\mathrm{~mol} \mathrm{~m}^{-3} \mathrm{~s}^{-1}\right]$ & $R_{\mathrm{ini}}^{* 1620}\left[\mathrm{~mol} \mathrm{~m}^{-3} \mathrm{~s}^{-1}\right]$ & $K_{\mathrm{ini}}^{* 1637}\left[\mathrm{~mol} \mathrm{~m}^{-3 / 2} \mathrm{~s}^{-1 / 2}\right]$ & $K_{\mathrm{ini}}^{* 1620}\left[\mathrm{~mol} \mathrm{~m}^{-3 / 2} \mathrm{~s}^{-1 / 2} \mathrm{~J}^{-1 / 2}\right]$ & $K_{\mathrm{ini}}^{* 1637} / K_{\mathrm{ini}}^{* 1620}$ \\
\hline 315 & 6.4 & 3.5 & $3.4 \times 10^{-4}$ & $1.90 \times 10^{-4}$ & $0.4 \times 10^{-4}$ \\
365 & 0.39 & 0.21 & $0.7 \times 10^{-4}$ & $0.02 \times 10^{-4}$ \\
408 & 0.016 & 0.0081 & $0.04 \times 10^{-4}$ & $0.16 \times 10^{-4}$ \\
545 & 0.061 & 0.037 & $0.26 \times 10^{-4}$ & $4 \times 10^{-4}$ \\
650 & 0.31 & 0.23 & $6 \times 10^{-4}$ & 1.9 \\
\hline
\end{tabular}

${ }^{\mathrm{a}} \mathrm{MPS} / \mathrm{Sb}: \mathrm{SnO}_{2}=0.19 \mathrm{~g} / \mathrm{g} ; c_{\text {particle }}=10 \mathrm{vol} \%$.

${ }^{\mathrm{b}}$ The $R_{\mathrm{ini}}^{*}$ are $R_{\mathrm{ini}}$ values corrected for differences in $I_{0}$. The $K_{\mathrm{ini}}^{*}$ values and $K_{\mathrm{ini}}^{*}$ ratios were calculated from the corresponding $R_{\mathrm{ini}}^{*}$ values shown.

liquid monomer, and quantitatively reproducible data were not obtained by us for the $\mathrm{C}=\mathrm{C}$ bond disappearance rates when $\mathrm{Sb}: \mathrm{SnO}_{2}$ particles without MPS grafting were used in our experiments. Therefore, in general, starting formulations containing MPS grafted $\mathrm{Sb}: \mathrm{SnO}_{2}$ particles were used.

The amount of methacrylate (MPS) moieties grafted on the surface of our $\mathrm{Sb}: \mathrm{SnO}_{2}$ particles surface and the amount of methacrylate (MPS) oligomer present in the starting formulation depend on the MPS/Sb: $\mathrm{SnO}_{2}$ ratio used in the grafting reaction (Schemes 2 and 3) [2, 12, 22, 25]. It has been shown that these amounts are hardly influenced by the surface and bulk composition of our $\mathrm{Sb}: \mathrm{SnO}_{2}$ nanoparticles (Scheme 3). The results for starting mixtures containing $\mathrm{Sb}: \mathrm{SnO}_{2}(\mathrm{Sb}=7 \%)$ particles which were grafted in advance with variable $\mathrm{MPS} / \mathrm{Sb}: \mathrm{SnO}_{2}$ ratios (MPS/Sb: $\mathrm{SnO}_{2} \geq 0$ ) are shown in Figure 5(a). The largest influence is found when a monolayer of MPS is present (MPS/Sb: $\mathrm{SnO}_{2} \geq$ $0.08 \mathrm{~g} / \mathrm{g})$. The influence of MPS oligomer seems to be small (Scheme 3).
To calculate the rate constants for the different starting mixtures of Figure 5(a), a variation in the (meth)acrylate $\mathrm{C}=\mathrm{C}$ bond concentration at the start of the reaction has to be taken into account. As the molecular weight and the number of $\mathrm{C}=\mathrm{C}$ double bonds of these monomers/moieties are different, a change in the MPS/PEGDA ratio will change the total double bond concentration $c_{(\mathrm{C}=\mathrm{C}) t=0}$. To facilitate the interpretation of these results (2)-(4) were modified into (5)-(7) using (8):

$$
\begin{aligned}
R_{\text {ini }}^{m \lambda}= & \left\{K_{\text {ini }}^{\lambda}\left(c_{\mathrm{c}=\mathrm{c}}\right)_{t}-\left(c_{\mathrm{c}=\mathrm{c}}\right)_{t=0}\right\}\left\{\left(c_{\mathrm{c}=\mathrm{c}}\right)_{t=0}\right\}^{-1} \\
& \times\left\{I_{0}\left(1-10^{-\varepsilon(\lambda) \cdot c_{\text {particle }} \cdot d}\right) d^{-1}\right\}^{1 / 2}, \\
R_{\max }^{m} \lambda= & K_{\max }^{\lambda}\left\{c_{(\mathrm{c}=\mathrm{c}) t 1}-c_{(\mathrm{c}=\mathrm{c}) t 2}\right\}\left\{\left(c_{\mathrm{c}=\mathrm{c}}\right)_{t=0}\right\}^{-1} \\
& \times\left\{I_{0}\left(1-10^{-\varepsilon(\lambda) \cdot c_{\text {particle }} \cdot d}\right) d^{-1}\right\}^{1 / 2},
\end{aligned}
$$




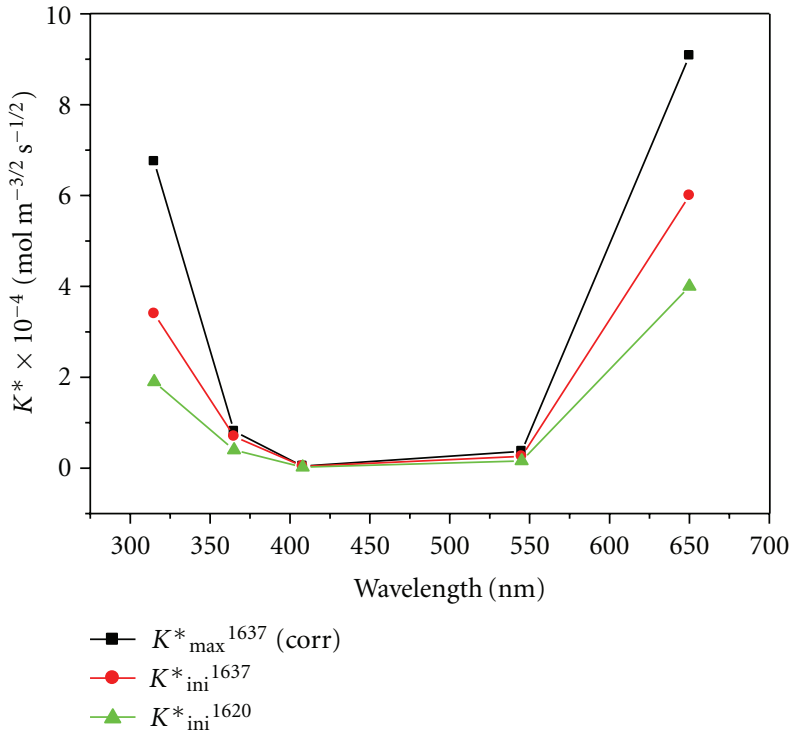

(a)

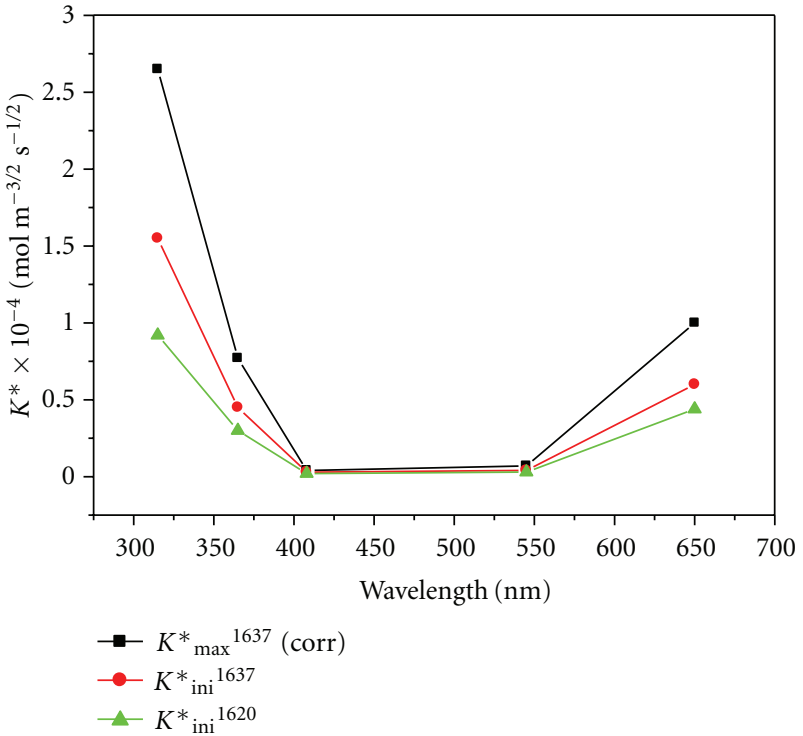

(b)

FIgURE 4: The influence of the wavelength of illumination on the $K^{*}$ values for starting MPS-Sb:SnO $2 / \mathrm{PEGDA}$ formulations against the wavelength of radiation $\lambda$ (nm). (a) $\mathrm{Sb}=0 \%$; (b) $\mathrm{Sb}=7 \%$.

$$
\begin{aligned}
& K_{\text {ini/max }}^{\lambda, m} \\
& =K_{\text {ini } / \max }^{\lambda}\left\{\left(c_{\mathrm{c}=\mathrm{c}}\right)_{t=0}\right\}^{-1} \\
& =k_{p(\text { ini } / \max )}^{\lambda}\left\{\Phi^{\lambda}\left(k_{t(\text { ini } / \max )}^{\lambda}\right)^{-1}\right\}\left\{\left(c_{\mathrm{c}=\mathrm{c}}\right)_{t=0}\right\}^{-1}, \\
& R_{\text {ini/max }}^{\lambda, m}=R_{\text {ini/max }}^{\lambda}\left\{\left(c_{\mathrm{c}=\mathrm{c}}\right)_{t=0}\right\}^{-1} .
\end{aligned}
$$

This means that the presented $R_{\mathrm{ini} / \max }^{m}$ values in Table 4 using incident radiation of $365 \mathrm{~nm}$ depend not only on the concentration of the $\mathrm{C}=\mathrm{C}$ double bonds at time $t$ or $t_{\max }\left\{t_{\max }=\left(t_{1}-t_{2}\right) / 2\right\}$ but also on the $\mathrm{C}=\mathrm{C}$ bond concentration at time $t=0$. The corrected $K_{\text {ini/max }}^{m}$ values are shown in Table 4 and Figure $5(\mathrm{~b})$ as $K_{\mathrm{ini} / \max }^{* *}$.

Figure 5(b) shows that the $K_{\max }^{* *}$ values determined at $1637 \mathrm{~cm}^{-1}$ are, within experimental error, identical to those determined at $1620 \mathrm{~cm}^{-1}$. The acrylate $\mathrm{C}=\mathrm{C}$ bonds absorb at $1620 \mathrm{~cm}^{-1}$ and both methacrylate $\mathrm{C}=\mathrm{C}$ and acrylate $\mathrm{C}=\mathrm{C}$ bonds at $1637 \mathrm{~cm}^{-1}$. Hence, these $K_{\max }^{* *}$ values are the relative quantum yields for the reaction between a polymer fragment with an acrylate radical end group and an acrylate $\mathrm{C}=\mathrm{C}$ bond. The $K_{\max }^{* *}$ values are hardly influenced when the particles are grafted with an monolayer of MPS (MPS/Sb: $\mathrm{SnO}_{2}$ ratios $\geq 0.08$ ). Variable amounts of MPS oligomer are present in these starting formulations, but they seem not to influence these $K_{\max }^{* *}$ values. When the surface of the particles is covered with less than a monolayer MPS (MPS/Sb: $\mathrm{SnO}_{2}$ ratio $<0.08)$, the rate is increased showing that the amount of grafted MPS influences these $K^{* *}$ values. Figure 5(b) also shows that the $K_{\text {ini }}^{* *}$ values are always lower than the $K_{\max }^{* *}$ values. These lower values were also reported earlier for similar formulations when radiation of $315 \mathrm{~nm}$ was used and can be explained by the large preference of a methacrylate radical end group to react with a methacrylate $\mathrm{C}=\mathrm{C}$ double bond. This results into lower $K_{\text {ini }}^{* *}$ values and a preferred consumption of the methacrylate $\mathrm{C}=\mathrm{C}$ bonds (different $k_{p} / \sqrt{ } k_{t}$ values) at the initial stage of the reaction. This preference, which is discussed above in more detail, is well known for radical polymerizations in methacryl/acryl $\mathrm{C}=\mathrm{C}$ bond mixtures $[12,14,32]$. The influence of the $k_{p} / \sqrt{ } k_{\mathrm{t}}$ values at the initial stage of the reaction becomes larger when the amount of methacrylate MPS $\mathrm{C}=\mathrm{C}$ bonds present is larger (Figure 5(b), Table 4). The similarity found for the ratios of $K_{\mathrm{ini}}^{*}{ }^{1637} / K_{\mathrm{ini}}^{*}{ }^{1620}$ can only be explained by a lowering of the $\Phi_{\mathrm{Sb}=7 \%}^{365}$ when increasing amounts of $\mathrm{MPS} / \mathrm{Sb}: \mathrm{SnO}_{2}$ ratios are used in the grafting reaction of the particles.

When the particles are not grafted with MPS the reproducibility in the measured $\mathrm{C}=\mathrm{C}$ rates is much lower, because of the variation in the agglomeration of the nanoparticles before and during the reaction. Still the $K_{\text {ini }}$ values calculated for the nongrafted particles are always much larger than those for the nanoparticles grafted with MPS. This confirms that the grafting of the surface of the $\mathrm{Sb}: \mathrm{SnO}_{2}$ particles lowers $\Phi_{\mathrm{Sb}=7 \%}^{365}$. Similar influences of the MPS/Sb: $\mathrm{SnO}_{2}$ ratios on the rate of $\mathrm{C}=\mathrm{C}$ bond disappearance were reported when the formulations containing $\mathrm{Sb}: \mathrm{SnO}_{2} \quad(\mathrm{Sb}=0 \%)$ particles were irradiated with $315 \pm 5 \mathrm{~nm}$ [12]. Hence, it is likely that MPS grafting of the surface of the $\mathrm{Sb}: \mathrm{SnO}_{2}(\mathrm{Sb}$ $\geq 0 \%$ ) nanoparticles lowers the quantum efficiency of the formation of the initiating radical for $\mathrm{C}=\mathrm{C}$ polymerization for all irradiating wavelengths of light between 300 and $650 \mathrm{~nm}$.

After irradiation with $315,365,408,545$, or $650 \mathrm{~nm}$, we always obtained a hard transparent thin layer (trans- 
TABle 4: The influence of the MPS/Sb: $\mathrm{SnO}_{2}$ grafting ratio on the $K_{\mathrm{ini}}^{m}, K_{\mathrm{ini}}^{* *} / K_{\mathrm{ini}}^{* *}$, and $K_{\mathrm{ini}}^{* *} / K_{\mathrm{ini}}^{* *}$ for $\mathrm{Sb}: \mathrm{SnO}_{2} / \mathrm{PEGDA} 575$ formulations. ${ }^{\text {a }}$

\begin{tabular}{|c|c|c|c|c|c|c|}
\hline $\mathrm{MPS} / \mathrm{Sb}: \mathrm{SnO}_{2}$ & $R_{\mathrm{ini}}^{m}{ }^{1637}\left[\mathrm{~s}^{-1}\right]$ & $R_{\mathrm{ini}}^{m}{ }^{1620}\left[\mathrm{~s}^{-1}\right]$ & $R_{\max }^{m} 1637\left[\mathrm{~s}^{-1}\right]$ & $R_{\max }^{m}{ }^{1620}\left[\mathrm{~s}^{-1}\right]$ & $K_{\text {ini }}^{* * 1637} / K_{\max }^{* *} 1637$ & $K_{\mathrm{ini}}^{* * 1637} / K_{\mathrm{ini}}^{* * 1620}$ \\
\hline 0 & $(0.020)^{\mathrm{b}}$ & $(0.023)^{\mathrm{b}}$ & & & & $(0.90)^{\mathrm{a}}$ \\
\hline 0.051 & 0.012 & 0.011 & 0.024 & 0.025 & 0.42 & 1.1 \\
\hline 0.080 & 0.011 & 0.0084 & 0.020 & 0.020 & 0.41 & 1.2 \\
\hline 0.12 & 0.0098 & 0.0090 & 0.019 & 0.020 & 0.41 & 1.1 \\
\hline 0.15 & 0.0095 & 0.0077 & 0.016 & 0.016 & 0.48 & 1.3 \\
\hline 0.196 & 0.0038 & 0.0093 & 0.017 & 0.018 & 0.55 & 1.5 \\
\hline
\end{tabular}

${ }^{\mathrm{a}} \mathrm{Sb}=7 \%$, incident wavelength of radiation $365 \pm 5 \mathrm{~nm} .{ }^{\mathrm{b}}$ Experimental error above $40 \%$.

parency $>98 \%$, haze < 1\%) when MPS grafted $\mathrm{Sb}: \mathrm{SnO}_{2}$ $(\mathrm{Sb}>0 \%)$ nanoparticles were used in PEGDA 575 starting formulations which did not contain any other photocatalytic molecule/particle. The layers were so hard because the MPS grafted surface groups also reacted and the nanoparticles were chemically connected to the polymer network and were forming cross-links through the polymer matrix. The methacrylate $\mathrm{C}=\mathrm{C}$ bonds present react at the initial stage of the polymerization reaction. Hence, the structure of the polymer network formed at the end of the cure will depend on the ratio between methacrylate $\mathrm{C}=\mathrm{C}$ and acrylate $\mathrm{C}=\mathrm{C}$ bonds initially present in the formulation.

When $\mathrm{Sb}: \mathrm{SnO}_{2}(\mathrm{Sb} \geq 0 \%)$ nanoparticles, of which the surfaces were not grafted with MPS, were used in these PEGDA 575 starting formulations viscous thin layers are obtained after cure. These layers are no longer transparent. The particles agglomerate further during the cure and become visible for the eye. At the end of the cure reaction, still a large number of acrylate $\mathrm{C}=\mathrm{C}$ bonds are present (Figure 5(a)).

In the experiments discussed above incident radiation with a very narrow wavelength distribution was used. We found the same photocatalytic properties for (MPS)$\mathrm{Sb}: \mathrm{SnO}_{2}(\mathrm{Sb} \geq 0 \%)$ particles when in our experiments incident radiation with a broad wavelength distribution (visible or ultraviolet $>300 \mathrm{~nm}+$ visible) was used. However, the overall efficiency of the photocatalyzed polymerization, the structure of the polymer, and the particle network formed through the layer depended on the wavelength and intensity distribution of the lamp used in the experiment.

3.3. Influence of $S b$-Doping. In this section the influence of Sb-doping (0-13 vol.\%) on the photocatalytic properties of the $\mathrm{Sb}: \mathrm{SnO}_{2}$ nanoparticles is discussed. All the $\mathrm{Sb}: \mathrm{SnO}_{2} /$ PEGDA formulations discussed in this chapter contain $\mathrm{Sn}: \mathrm{SbO}_{2}$ particles which are covered with a monolayer of grafted MPS and contain very similar amounts of MPS oligomer. For all these formulations the $\left(C_{\mathrm{c}=\mathrm{c}}\right)_{t=0}$ is the same. These formulations are irradiated with light of 315 or $365 \mathrm{~nm}$, and the measured relative conversions of the $\mathrm{C}=\mathrm{C}$ bonds over time at $1637 \mathrm{~cm}^{-1}$ are shown in Figures 6(a) and 6(b), respectively. The corresponding $R$ and $K$ data are shown in Figure 7 after correcting them for differences in incident radiation intensities and in absorption coefficients of the $\mathrm{Sb}: \mathrm{SnO}_{2}$ particles $\left(R_{\mathrm{ini}}^{*}, R_{\mathrm{max}}^{*}, K_{\mathrm{ini}}^{*}\right.$, and $\left.K_{\max }\right)$ (Table 2, Figure 2).
The presented conversions in Figure 6 show that for all $\mathrm{Sb}$-doping levels the rates of the $\mathrm{C}=\mathrm{C}$ bond polymerization are always much faster for irradiation with $315 \mathrm{~nm}$ than those with $365 \mathrm{~nm}$. This is confirmed by the calculated $K^{*}$ values shown in Figure 7 . For both incident wavelengths of radiation used the $K_{\max }^{*}{ }^{1637}$ and $K_{\max }^{*}{ }^{1620}$ values for particles with $\mathrm{Sb} \geq 2 \%$ are, within experimental error, identical. Hence, all these $K$ values are the relative quantum efficiencies of the propagation and termination reaction of a polymer fragment with an acrylate radical end group and a $\mathrm{C}=\mathrm{C}$ acrylate monomer. This suggests that the observed dependence of $K_{\max }^{*}$ on Sb-doping should be explained by the dependency of $\Phi$ on Sb-doping.

Figure 7 also shows that the $K_{\text {ini }}^{*}$ values measured at $1637 \mathrm{~cm}^{-1}$ are always much larger than the $K_{\text {ini }}^{*}$ values measured at $1620 \mathrm{~cm}^{-1}$. Hence, at the initial stage of the polymerization reaction methacrylate radicals and $\mathrm{C}=\mathrm{C}$ bonds as well as acrylate radicals and $\mathrm{C}=\mathrm{C}$ bonds are involved in the formation of the polymer. Although the methacrylate $\mathrm{C}=\mathrm{C}$ bond concentration is only about one tenth of the total $\mathrm{C}=\mathrm{C}$ bond concentration in these mixtures, the reaction between a methacryl radical and a methacryl $\mathrm{C}=\mathrm{C}$ bond is preferred $[12,14,32]$. Still the ratios $K_{\text {ini }}^{* 1637} / K_{\max }^{*} 1637$ and $K_{\text {ini }}^{*}{ }^{1637} / K_{\text {ini }}^{*}{ }^{1620}$ are within experimental error independent of the $\mathrm{Sb}$-doping level and wavelength of radiation (Table 5).

Hence, also at the initial stage of the polymerization reactions the variations in $K_{\text {ini }}^{*}$ presented in Figure 7 with respect to $\mathrm{Sb}$-doping level are likely to be caused by variations in $\Phi$ only. This suggests that these $K$ values can be corrected for corresponding $k_{p}\left(k_{\mathrm{t}}\right)^{-1 / 2}$ values of the polymerization reaction between a polymer fragment with an acrylate end group and an acrylate $\mathrm{C}=\mathrm{C}$ bond. Using this approach and the data of Table 3 and Figure 7 , the ratios between the different $\Phi$ values for different Sb-doping levels are calculated and presented in Table 5. These data confirm that our $\mathrm{Sb}$-doped $\mathrm{Sb}: \mathrm{SnO}_{2}$ nanoparticles always have a lower $\Phi$ and that the influence on $\Phi$ of Sb-doping strongly depends on the wavelength of light used. For a fixed wavelength the differences in $\Phi$ for particles with $\mathrm{Sb} \geq 2 \%$ are small. Combining the data of Table 5 with the data reported earlier for particles with $\mathrm{Sb}$ of $7 \%$ and $0 \%$, the ratios of both $\Phi$ 's are calculated for visible light too (Figure 8). From this graph we conclude that the influence of Sb-doping on $\Phi$ is strongly dependent on the wavelength of irradiation used. For each wavelength the value of $\Phi$ is always larger for formulations with $\mathrm{Sb}: \mathrm{SnO}_{2}(\mathrm{Sb}=0 \%)$ than for formulations 


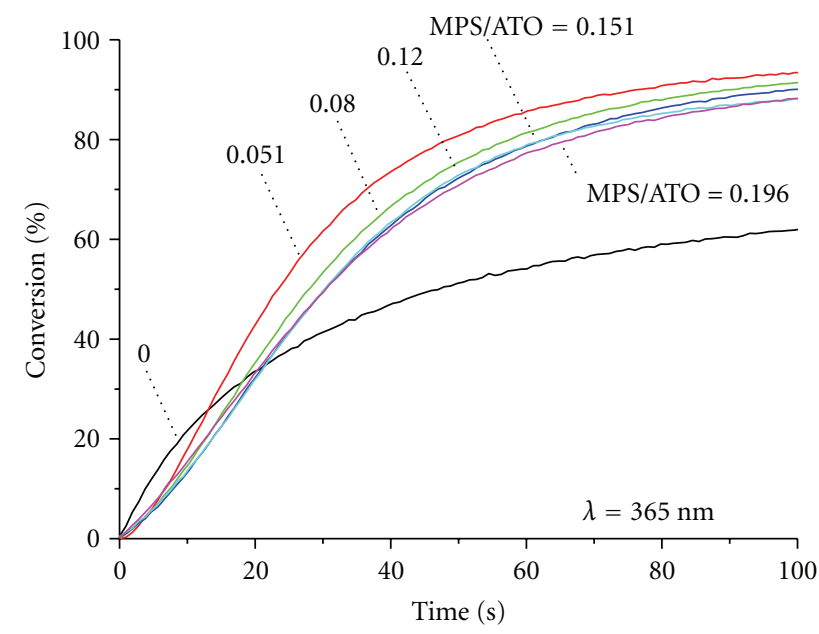

(a)

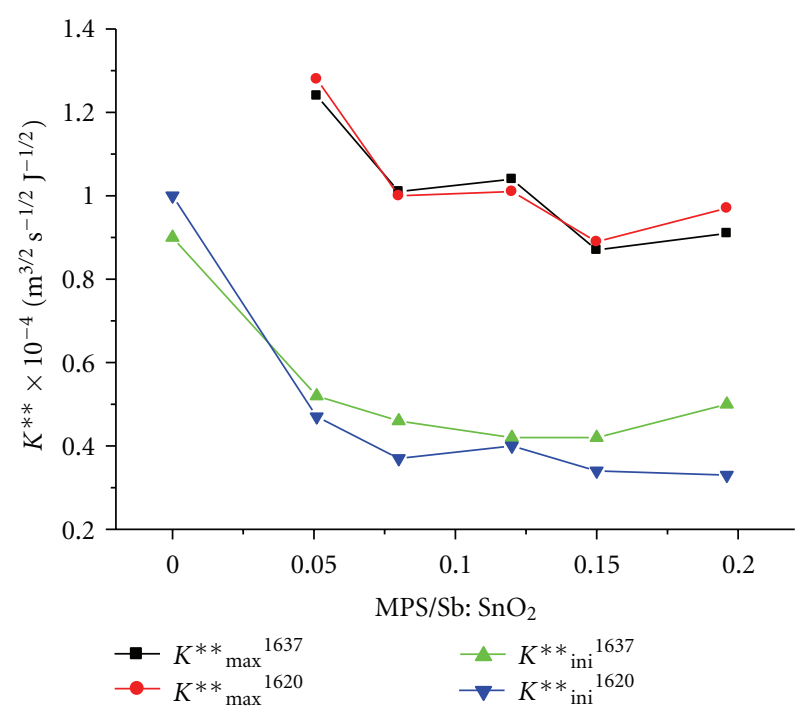

(b)

FIGURE 5: (a) Influence of the amount of MPS present in the starting formulation on the conversion $\%$ of the $\mathrm{C}=\mathrm{C}$ bonds over time; $\lambda=$ $365 \mathrm{~nm}, \mathrm{Sb}=7 \%$, and $c_{\text {particle }}=10$ vol $\%$. (b) $K^{* *}$ values calculated from (a).

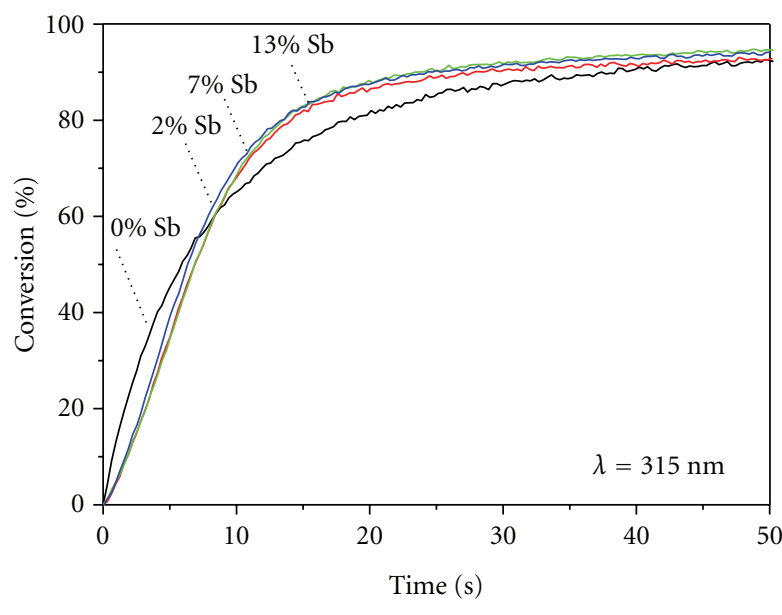

(a)

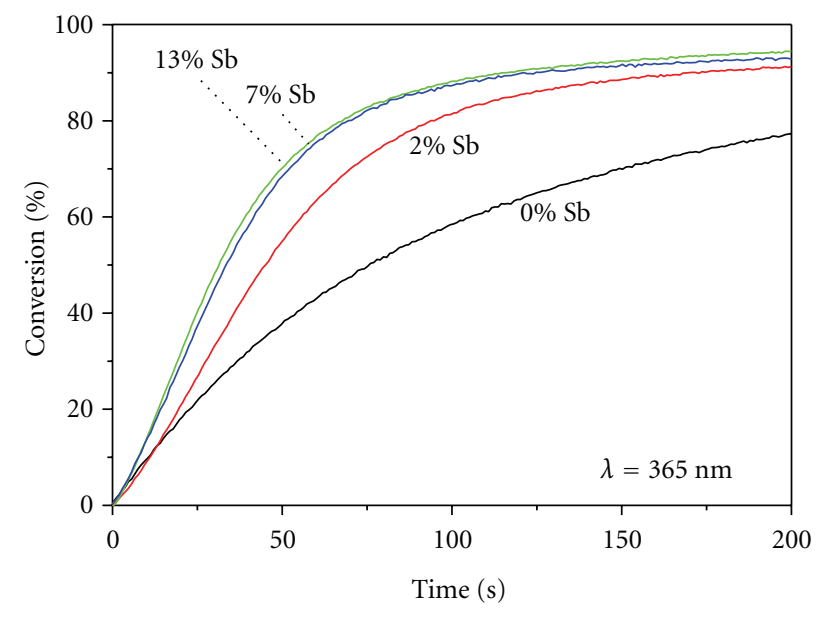

(b)

Figure 6: Influence of the Sb-doping level of the nanoparticles on the conversion $\%$ of the $\mathrm{C}=\mathrm{C}$ bonds over time measured at $1637 \mathrm{~cm}^{-1}$. (a) $\lambda=315 \mathrm{~nm}$; (b) $\lambda=365 \mathrm{~nm}$.

TABLE 5: Influence of Sb-doping on $K_{\mathrm{ini}}^{* 1637} / K_{\max }^{*}{ }^{1637}$ and $K_{\mathrm{ini}}^{* 1637} / K_{\mathrm{ini}}^{* 1620} ; \lambda=315$ or $365 \mathrm{~nm}$.

\begin{tabular}{|c|c|c|c|c|}
\hline$\lambda[\mathrm{nm}]$ & $\mathrm{Sb} \%$ & $K_{\mathrm{ini}}^{* 1637} / K_{\max }^{*}{ }^{1637}$ & $K_{\mathrm{ini}}^{* 1637} / K_{\mathrm{ini}}^{* 1620}$ & $\Phi_{\mathrm{Sb} \geq 2 \%} / \Phi_{\mathrm{Sb}=0 \%}{ }^{\mathrm{a}}$ \\
\hline 315 & 0 & & 1.8 & \\
\hline 365 & 0 & & 1.8 & \\
\hline 315 & 2 & 0.6 & 1.8 & 0.35 \\
\hline 365 & 2 & 0.6 & 1.8 & 0.68 \\
\hline 315 & 7 & 0.6 & 1.7 & 0.40 \\
\hline 365 & 7 & 0.6 & 1.6 & 0.90 \\
\hline 315 & 13 & 0.5 & 1.5 & 0.46 \\
\hline 365 & 13 & 0.6 & 1.6 & 0.74 \\
\hline
\end{tabular}

${ }^{\mathrm{a}} K^{*}$ values corrected for differences in $k_{p}\left(k_{\mathrm{t}}\right)^{-1 / 2}$. 


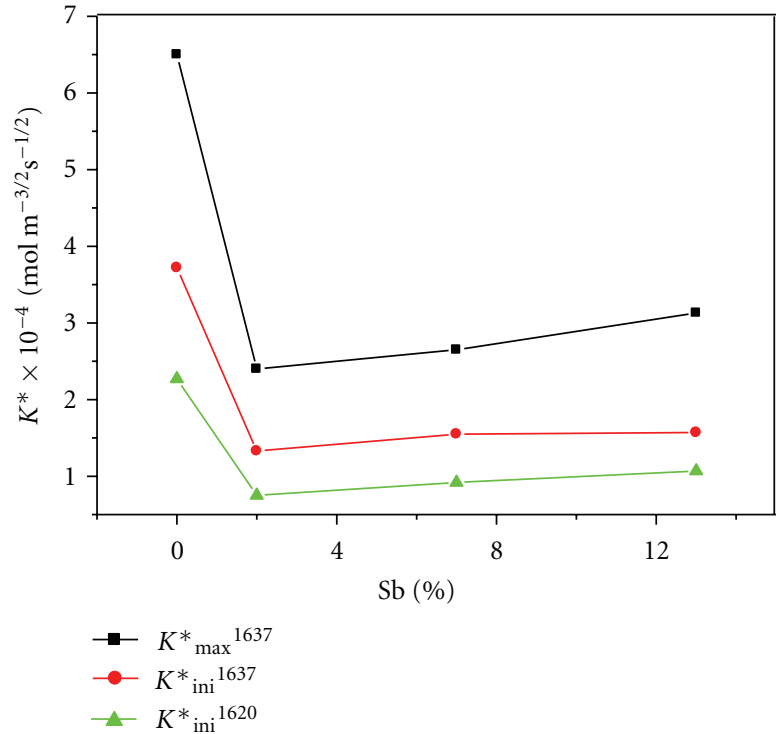

(a)

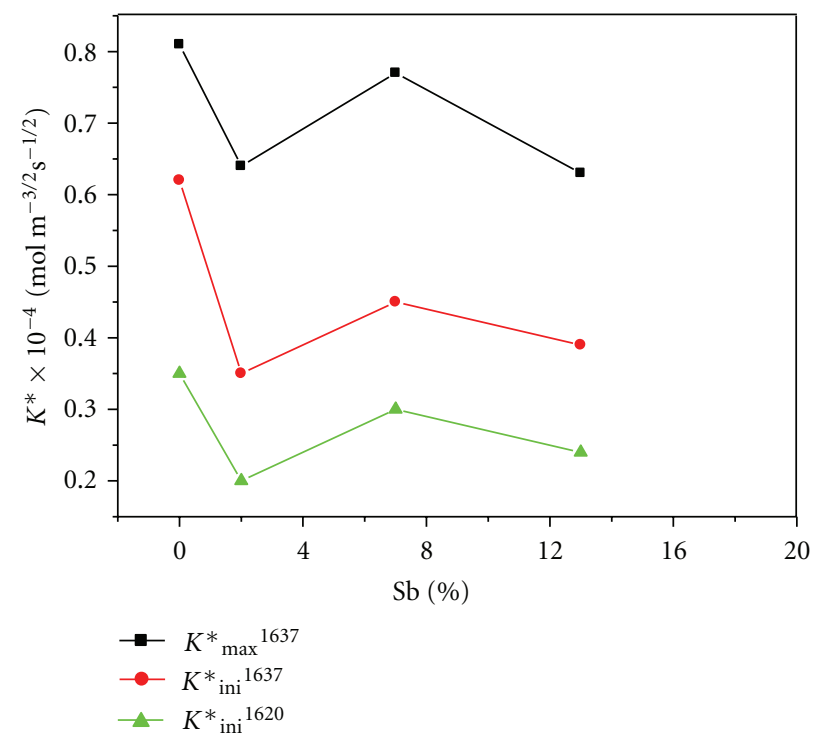

(b)

FIgURE 7: The influence of the Sb-doping level on $K_{\max }^{*}{ }^{1637}, K_{\max }^{*}{ }^{1637}$, and $K_{\mathrm{ini}}^{* 1620}$ calculated from the data given in Figure 6. When Sb $=0 \%$ the $K_{\max }^{*}{ }^{1637}$ values shown are actually the $K_{\max }^{*}{ }^{1637}$ (corr.) values. (a) $\lambda=315 \mathrm{~nm}$; (b) $\lambda=365 \mathrm{~nm}$.

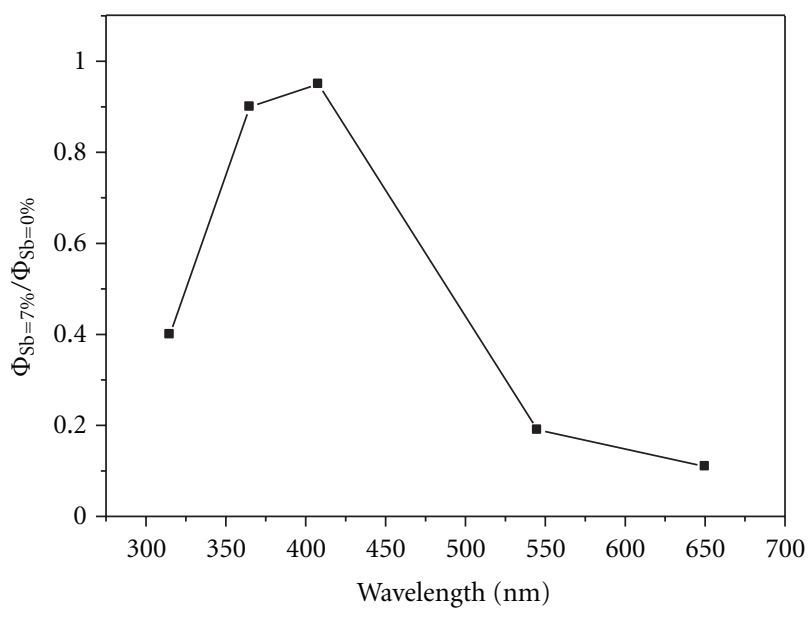

Figure 8: The dependency of the ratio $\Phi_{\mathrm{Sb}=7 \%} / \Phi_{\mathrm{Sb}=0 \%}$ versus the wavelength of illumination.

with $\mathrm{Sb}: \mathrm{SnO}_{2}(\mathrm{Sb} \geq 2 \%)$. These data also suggest that further optimization of the amount of Sb-doping and of $\mathrm{N}$-doping (see also later on) used may enlarge the $\Phi$ for visible light of $\mathrm{Sb}: \mathrm{SnO}_{2}(\mathrm{Sb}>0 \%)$ nanoparticles considerably.

3.4. Why Is $\Phi$ Dependent on the Wavelength of Irradiation, MPS Grafting and Sb Doping? We showed above that the $\Phi$ 's for the formation of the radical, which initiates the (meth)acrylate $\mathrm{C}=\mathrm{C}$ bond polymerization, are dependent on the wavelength of illumination used, the amount of the methacrylate group grafted on the particle surface, and the Sb-doping level of the particles. The MPS-Sb:SnO nanoparticles used are (almost) monocrystalline, have a similar surface area and are well dispersed in the formulations before and during processing (Table 1) $[12,13]$. Hence, the observed differences in quantum yields are mainly related to differences in surface and/or bulk group composition of these nanoparticles.

Undoped $\mathrm{SnO}_{2}$ particles/films are, in general, n-type semiconductive materials due to native oxygen vacancies. They have a band gap of $3.6 \mathrm{eV}-3.8 \mathrm{eV}$ and a Fermi level of about $0.35-0.5 \mathrm{eV}$ below the conduction band $[16,17]$. This band gap difference corresponds with light quanta energies between 320 and $340 \mathrm{~nm}$. When the $\mathrm{Sb}: \mathrm{SnO}_{2}(\mathrm{Sb}-$ $0 \%$ )/PEGDA formulations are irradiated with light of 315 $\mathrm{nm}$, the photocatalytic properties are explained by a direct transfer of an electron from the valence band into the conduction band. However, for irradiation wavelengths $\geq 365 \mathrm{~nm}$, the energy of the light quant is too small to initiate this transition and the observed photocatalytic properties of the $\mathrm{Sb}: \mathrm{SnO}_{2}$ particles at or above $365 \mathrm{~nm}$ have to be explained differently.

Recently it has been shown that N-doping can shift the band gap of crystalline $\mathrm{SnO}_{2}$ films to $624 \mathrm{~nm}$ and that these $\mathrm{N}$-doped films photocatalyze the oxidation of methylene blue in water during irradiation with visible light [19]. The authors detected in the XPS spectra of these films three N $1 \mathrm{~s}$ related peaks, namely, at 396, 399, and $402 \mathrm{eV}$. They suggest that the energy level related to the peak at $396 \mathrm{eV}$ is the one responsible for the observed photocatalysis under visible illumination. All our $\mathrm{Sb}: \mathrm{SnO}_{2}$ nanoparticles are doped with $\mathrm{N}$ (Table 1), but in their XPS spectra only one broad peak at about $400 \mathrm{eV}$ and no signal at $396 \mathrm{eV}$ is observed (Figure 9). The peak at $400 \mathrm{eV}$ is likely to be a combination of two peaks (399 and $402 \mathrm{eV}$ ). The maximum of this broad peak 


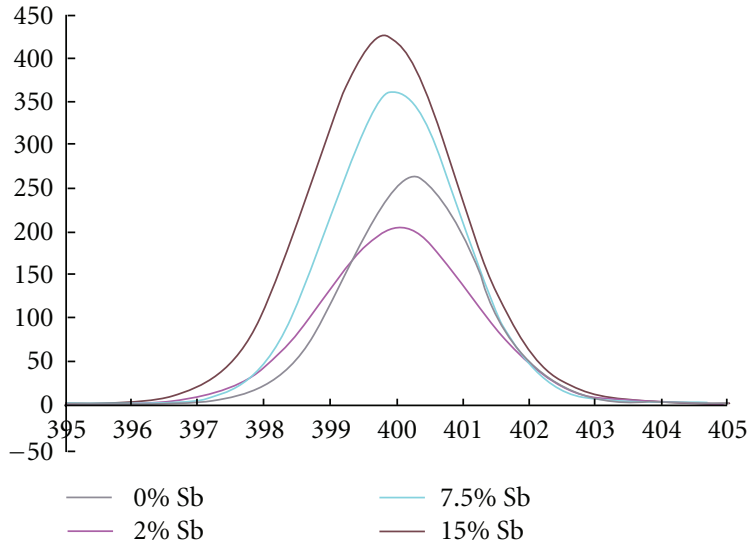

(a)

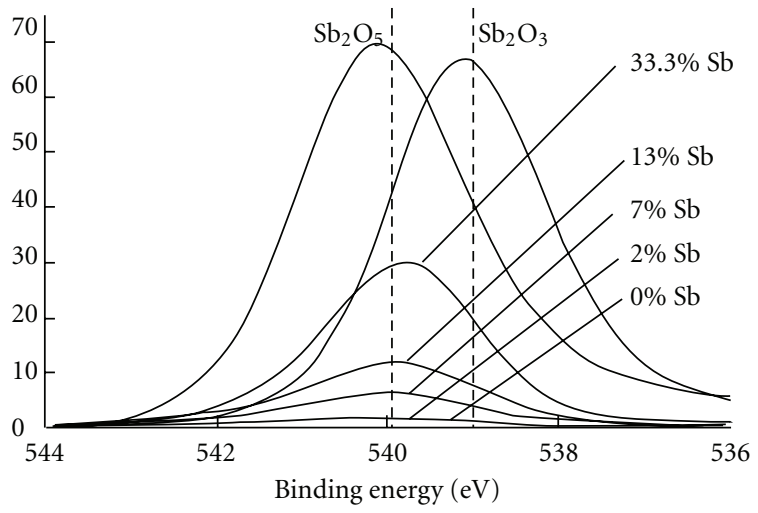

(b)

FIgURE 9: (a) XPS spectra of the $\mathrm{N}$ 1s band of the $\mathrm{Sb}: \mathrm{SnO}_{2}$ nanoparticles; (b) XPS spectra of the $\mathrm{Sb}_{3 / 2}$ of several $\mathrm{Sb}: \mathrm{SnO}_{2}$ nanoparticles.

gradually shifts to $399 \mathrm{eV}$ when the Sb-doping level of the nanoparticles is increased, which can be explained by a dependency of the intensities of the 399 and $402 \mathrm{eV}$ peaks and of the concentrations of the two $\mathrm{N}$ forms in the bulk on Sb-doping level. Hence, it is likely that for our nanoparticles the energy levels related to the 399 and/or $402 \mathrm{eV}$ peaks initiate the photocatalyzed $\mathrm{C}=\mathrm{C}$ bond polymerizations for radiation wavelengths $\geq 365 \mathrm{~nm}$. XPS is a surface technique, and its penetration depth of a few nanometers will not probe the whole volume of our particles (diameter about $7 \mathrm{~nm}$ ) or the crystalline $\mathrm{SnO}_{2}$ films mentioned above, and this may explain the discrepancies in energy levels from which the photocatalysis occurs in both materials.

Density functional theory calculations on different Ndoped $\mathrm{SnO}_{2}$ structures suggest that $\mathrm{N}$-doping raises the top level of the valence band, forms states in the gap between valence and conduction band, and may lower the bottom of the conduction band [32]. Hence, all these changes facilitate the visible light photocatalytic activities of the MPS$\mathrm{Sb}: \mathrm{SnO}_{2}(\mathrm{Sb}=0 \%)$ particles discussed here. Because after irradiation the number of electrons in the conduction band of our nanoparticles increased for all the wavelengths used (Figure 3), it is likely that the polymerization starts with a reaction with the activated electron in the conduction band.

As was reported earlier [13], our $\mathrm{Sb}: \mathrm{SnO}_{2}$ nanoparticles are semiconductive and contain only $\mathrm{Sb}(\mathrm{V})$ ions at lower Sbdoping levels. At higher doping level also $\mathrm{Sb}$ (III) is present, probably mainly near/at the surface of the particles (Table 1) $[12,16]$. The $\mathrm{Sb}(\mathrm{V})$ ions have probably replaced some $\mathrm{Sn}$ ions in the original crystal structure and have donated an extra electron to the conduction band upon substitutional replacement [16]. UPS EELS and photoemission measurements confirm the filling of the conduction band by Sbdoping and suggest a shift of the Fermi level into the conduction band and a band gap narrowing. The increase in number of electrons in the conduction band by Sb-doping has been confirmed for our nanoparticles by an increase in intensity/shift of the peak maximum of the plasmon band (Figure 3).
Band structure calculations at high Sb-doping levels in $\mathrm{SnO}_{2}$ ( $\mathrm{Sb}$ doping about 25\%) suggest the formation of a Sb 5s-like band in the $\mathrm{SnO}_{2}$ gap with a free electron character at the $\Gamma$-point. This could be a half filled metallic band below the conduction band. Hence, it is likely that the Sb-doping levels of our nanoparticles result into energy levels at or close to the conduction band $[16,33]$. These $\mathrm{Sb}(\mathrm{V})$ energy levels may be expected to be about $0.03 \mathrm{eV}$ to $0.15 \mathrm{eV}$ below the minimum of the conduction band [30, 34]. Moreover, we found that Sb-doping always lowers the $\Phi$ (Table 5, Figure 8). This suggests that $\mathrm{Sb}$-doping levels function as scavengers of the activated electrons in the conduction band. However, $\mathrm{Sb}$-doping lowers also the number of oxygen vacancies in $\mathrm{SnO}_{2}$ and seems to influence the ratio between the two Ndoping energy levels observed in our $\mathrm{Sb}: \mathrm{SnO}_{2}$ nanoparticles (Figure 9). These changes in bulk composition may be responsible for the lowering of $\Phi$ with Sb-doping, and then it is likely that a half filled band close to the conduction band or the lowering of the bottom of the conduction band is involved in shifting the absorption of the radiation to at least $650 \mathrm{~nm}$ and the occurrence of radical $\mathrm{C}=\mathrm{C}$ bond polymerization photocatalyzed by our $\mathrm{Sb}: \mathrm{SnO}_{2}(\mathrm{Sb} \geq 2 \%)$ nanoparticles for illuminations with light between 365 and $650 \mathrm{~nm}$. This half filled band may not be present at Sbdoping levels lower than $2 \%$.

Grafting the surface of the $\mathrm{Sb}: \mathrm{SnO}_{2}$ particles with MPS lowers $\Phi$. The lowest values are obtained when the surface is grafted with a monolayer of MPS. Still photocatalysis continues although at a lower rate. This may be explained by the initial formation of an MPS radical on the surface of the particle, which reacts further with a much slower rate with a $\mathrm{C}=\mathrm{C}$ double bond outside the particle as compared to a direct transfer of an electron from the particle surface to a $\mathrm{C}=\mathrm{C}$ bond outside the particle, even when almost all the methacrylate $\mathrm{C}=\mathrm{C}$ bonds are disappeared. Another explanation may be that the initially formed grafted MPS radical reacts first preferably with the other grafted MPS molecules forming a more or less closed chemically connected apolar acrylate shield, which limits later on the 
transfer of another electron after absorption of a new light quantum to the outside of the particle.

\section{Conclusions}

(1) By absorption of radiation of $365,408,545$, or $650 \pm 5 \mathrm{~nm} \mathrm{Sb}: \mathrm{SnO}_{2}(\mathrm{Sb} \geq 0 \%)$ nanoparticles photocatalyze the (meth)acrylate $\mathrm{C}=\mathrm{C}$ bond radical polymerization present in MPS-Sb: $\mathrm{SnO}_{2} /$ acrylate monomer starting formulations.

(2) Although the energy of the light quanta of these wavelengths is too small to directly activate an electron from the valence band into the conduction band, the shift in peak position and/or the increase in the absorption the plasmon band during illumination of these formulations suggest that still this polymerization starts with a transfer of an activated electron present in the conduction band of the particle to a $\mathrm{C}=\mathrm{C}$ double bond outside or at the surface of the MPS-Sb: $\mathrm{SnO}_{2}$ nanoparticle. All the nanoparticles studied are always doped with $\mathrm{N}$ in the bulk, in which energy levels may be responsible for these photocatalyzed $\mathrm{C}=\mathrm{C}$ bond polymerizations.

(3) The relative quantum efficiencies for the polymerization of the $\mathrm{C}=\mathrm{C}$ bonds can be determined quantitatively and depend on the quantum yields ( $\Phi$ 's) for the formation of the radical which initiates the polymerization and the rate constants of the propagating and terminating polymerization reactions.

(4) The $\Phi$ appears to be dependent on the wavelength of irradiation, the amount of Sb-doping, and the amount of MPS grafting of the particle surface.

(5) It is likely that methacrylate grafting of the surface of the $\mathrm{Sb}: \mathrm{SnO}_{2}(\mathrm{Sb} \geq 0 \%)$ nanoparticles lowers $\Phi$ for all irradiating wavelengths of light between 300 and $650 \mathrm{~nm}$. This may be explained by the scavenger role of the grafted MPS moieties on the surfaces of the nanoparticles for the activated electrons in the conduction band. MPS grafting of these particles is essential for obtaining transparent (>98\%) hard layers with a low haze $(<1 \%)$.

(6) Sb-doping always lowers $\Phi$. The decrease in $\Phi$ may be caused by a scavenging of the activated electrons by $\mathrm{Sb}$-doping energy levels. Sb-doping lowers also the number of oxygen vacancies in the $\mathrm{Sb}: \mathrm{SnO}_{2}(\mathrm{Sb}$ $>0 \%)$ nanoparticles. These oxygen vacancies may initiate the formation of other radicals, which can initiate also the $\mathrm{C}=\mathrm{C}$ bond polymerization reaction.

(7) MPS-Sb : $\mathrm{SnO}_{2}$ nanoparticles are attractive new photocatalysts under visible light to initiate the polymerization of (meth)acrylate monomers.

\section{References}

[1] A. Mills and S. K. Lee, "A web-based overview of semiconductor photochemistry-based current commercial applications,"
Journal of Photochemistry and Photobiology, vol. 152, no. 1-3, pp. 233-247, 2002.

[2] C. Damm, "An acrylate polymerisation initiated by iron doped titanium dioxide," Journal of Photochemistry and Photobiology, vol. 181, no. 2-3, pp. 297-305, 2006.

[3] A. J. Hoffman, H. Yee, G. Mills, and M. R. Hoffmann, "Photoinitiated polymerization of methyl methacrylate using Qsized ZnO colloids," Journal of Physical Chemistry, vol. 96, no. 13, pp. 5540-5546, 1992.

[4] R. Ojah and S. K. Dolui, "Photopolymerization of methyl methacrylate using dye-sensitized semiconductor based photocatalyst," Journal of Photochemistry and Photobiology, vol. 172, no. 2, pp. 121-125, 2005.

[5] Encyclopedia of Polymer Science and Technology, vol. 10, 2004.

[6] F. E. Osterloh, "Inorganic materials as catalysts for photochemical splitting of water," Chemistry of Materials, vol. 20, no. 1, pp. 35-54, 2008.

[7] R. Asahi, T. Morikawa, T. Ohwaki, K. Aoki, and Y. Taga, "Visible-light photocatalysis in nitrogen-doped titanium oxides," Science, vol. 293, no. 5528, pp. 269-271, 2001.

[8] W. S. Tung and W. A. Daoud, "A new approach toward nanosized ferrous ferric oxide and iron-doped titanium dioxide photocatalysts," Applied Materials \& Interfaces, vol. 1, pp. 2453-2461, 2009.

[9] J. Zhu, W. Zheng, B. He, J. Zhang, and M. Anpo, "Characterization of $\mathrm{Fe}$-TiO photocatalysts synthesized by hydrothermal method and their photocatalytic reactivity for photodegradation of XRG dye diluted in water," Journal of Molecular Catalysis, vol. 216, no. 1, pp. 35-43, 2004.

[10] U. Gesenhues, "Al-doped TiO pigments: influence of doping on the photocatalytic degradation of alkyd resins," Journal of Photochemistry and Photobiology, vol. 139, no. 2-3, pp. 243251, 2001.

[11] D. Wu, Y. Jiang, Y. Yuan, J. Wu, and K. Jiang, The Journal of Nanoparticle Research, vol. 13, no. 7, pp. 2875-2886, 2011.

[12] J. C. M. Brokken-Zijp, O. L. J. van Asselen, W. E. Kleinjan, R. van de Belt, and G. de With, "Photocatalysed (meth)acrylate polymerization by (antimony-doped) tin oxide nanoparticles and photoconduction of their crosslinked polymer nanoparticle composites," Journal of Nanotechnology, vol. 2010, Article ID 579708, 16 pages, 2010.

[13] W. E. Kleinjan, R. van de Belt, Z. Chen, and G. de With, "Antimony-doped tin oxide nanoparticles for conductive polymer nanocomposites," Journal of Materials Research, vol. 23, no. 3, pp. 869-880, 2008.

[14] W. Posthumus, UV-Curable Acrylate Metal Oxide Nanocomposite Coatings, Ph.D. thesis, Eindhoven University of Technology, Eindhoven, The Netherlands, 2004.

[15] W. Posthumus, P. C. M. M. Magusin, J. C. M. BrokkenZijp, A. H. A. Tinnemans, and R. Van Der Linde, "Surface modification of oxidic nanoparticles using 3-methacryloxypropyltrimethoxysilane," Journal of Colloid and Interface Science, vol. 269, no. 1, pp. 109-116, 2004.

[16] M. Batzill and U. Diebold, "The surface and materials science of tin oxide," Progress in Surface Science, vol. 79, no. 2-4, pp. 47-154, 2005.

[17] S. Shanthi, C. Subramanian, and P. Ramasamy, "Investigations on the optical properties of undoped, fluorine doped and antimony doped tin oxide films," Crystal Research and Technology, vol. 34, no. 8, pp. 1037-1046, 1999.

[18] D. Lin-Vien, N. B. Colthup, W. G. Fately, and J. C. Grasselli, The Handbook of Infrared and Raman Characteristic Frequencies of Organic Molecules, Academic Press, San Diego, Calif, USA, 1991. 
[19] S. S. Pan, Y. D. Shen, X. M. Teng et al., "Substitutional nitrogen-doped tin oxide single crystalline submicrorod arrays: vertical growth, band gap tuning and visible light-driven photocatalysis," Materials Research Bulletin, vol. 44, no. 11, pp. 2092-2098, 2009.

[20] S. S. Pan, Y. X Zhang, X. M. Teng, G. H. Li, and L. Li, "Optical properties of nitrogen-doped $\mathrm{SnO}_{2}$ films: effect of the electronegativity on refractive index and band gap," Journal of Applied Physics, vol. 103, no. 9, Article ID 93103, 2008.

[21] L. J. Huijbregts, H. B. Brom, J. C. M. Brokken-Zijp, W. E. Kleinjan, and M. A. J. Michels, "Dielectric quantification of conductivity limitations due to nanofiller size in conductive powders and nanocomposites," Physical Review, vol. 77, no. 7, Article ID 075322, 6 pages, 2008.

[22] C. McGinley, H. Borchert, M. Pflughoefft et al., "Dopant atom distribution and spatial confinement of conduction electrons in Sb-doped $\mathrm{SnO}_{2}$ nanoparticles," Physical Review, vol. 64, no. 24, Article ID 245312, 9 pages, 2001.

[23] T. Nütz, U. Z. Felde, and M. Haase, "Wet-chemical synthesis of doped nanoparticles: blue-colored colloids of n-doped $\mathrm{SnO}_{2}$ :Sb," Journal of Chemical Physics, vol. 110, no. 24, Article ID 12142, 9 pages, 1999.

[24] U. Zum Felde, M. Haase, and H. Weller, "Electrochromism of highly doped nanocrystalline $\mathrm{SnO}_{2}: \mathrm{Sb}$," Journal of Physical Chemistry, vol. 104, no. 40, pp. 9388-9395, 2000.

[25] V. A. Soloukhin, J. C. M. Brokken-Zijp, and G. De With, "Conductive ATO-acrylate nanocomposite hybrid coatings: experimental results and modeling," Journal of Polymer Science, vol. 45, no. 16, pp. 2147-2160, 2007.

[26] A. J. Hoffman, G. Mills, H. Yee, and M. R. Hoffmann, "Q-sized CdS: synthesis, characterization, and efficiency of photoinitiation of polymerization of several vinylic monomers," Journal of Physical Chemistry, vol. 96, no. 13, pp. 5546-5552, 1992.

[27] R. Mehnert, A. Pincus, I. Janorsky, R. Stowe, and A. Berejka, UV \& EB Curing Technology and Equipment, vol. 1, John Wiley \& Sons, Chichester, UK, 1998.

[28] G. R. Tryson and A. R. Shultz, "Calorimetric study of acrylate photopolymerization," Journal of Polymer Science, vol. 17, no. 12, pp. 2059-2075, 1979.

[29] J. Jansen, E. Houben, P. H. G. Tummers, D. Wienke, and J. Hoffmann, "Real-time infrared determination of photoinitiated copolymerization reactivity ratios: application of the Hilbert transform and critical evaluation of data analysis techniques," Macromolecules, vol. 37, no. 6, pp. 2275-2286, 2004.

[30] C. S. Rastomjee, R. G. Egdell, M. J. Lee, and T. J. Tate, "Observation of conduction electrons in Sb-implanted $\mathrm{SnO}_{2}$ by ultraviolet photoemission spectroscopy," Surface Science, vol. 259, no. 3, pp. L769-L773, 1991.

[31] F. Gu, S. F. Wang, M. K. Lü, G. J. Zhou, D. Xu, and D. R. Yuan, "Photoluminescence properties of $\mathrm{SnO}_{2}$ nanoparticles synthesized by sol-gel method," Journal of Physical Chemistry, vol. 108, no. 24, pp. 8119-8123, 2004.

[32] X. Sun, R. Long, X. Cheng, X. Zhao, Y. Dai, and B. Huang, "Structural, electronic, and optical properties of N-doped $\mathrm{SnO}_{2}$," Journal of Physical Chemistry, vol. 112, no. 26, pp. 9861-9864, 2008.

[33] K. C. Mishra, K. H. Johnson, and P. C. Schmidt, "Electronic structure of antimony-doped tin oxide," Physical Review, vol. 51, no. 20, pp. 13972-13976, 1995.

[34] C. G. Fonstadt and R. H. Redicker, "Electrical properties of high quality stannic oxide crystals," Journal of Applied Physics, vol. 42, no. 7, p. 2911, 1971. 

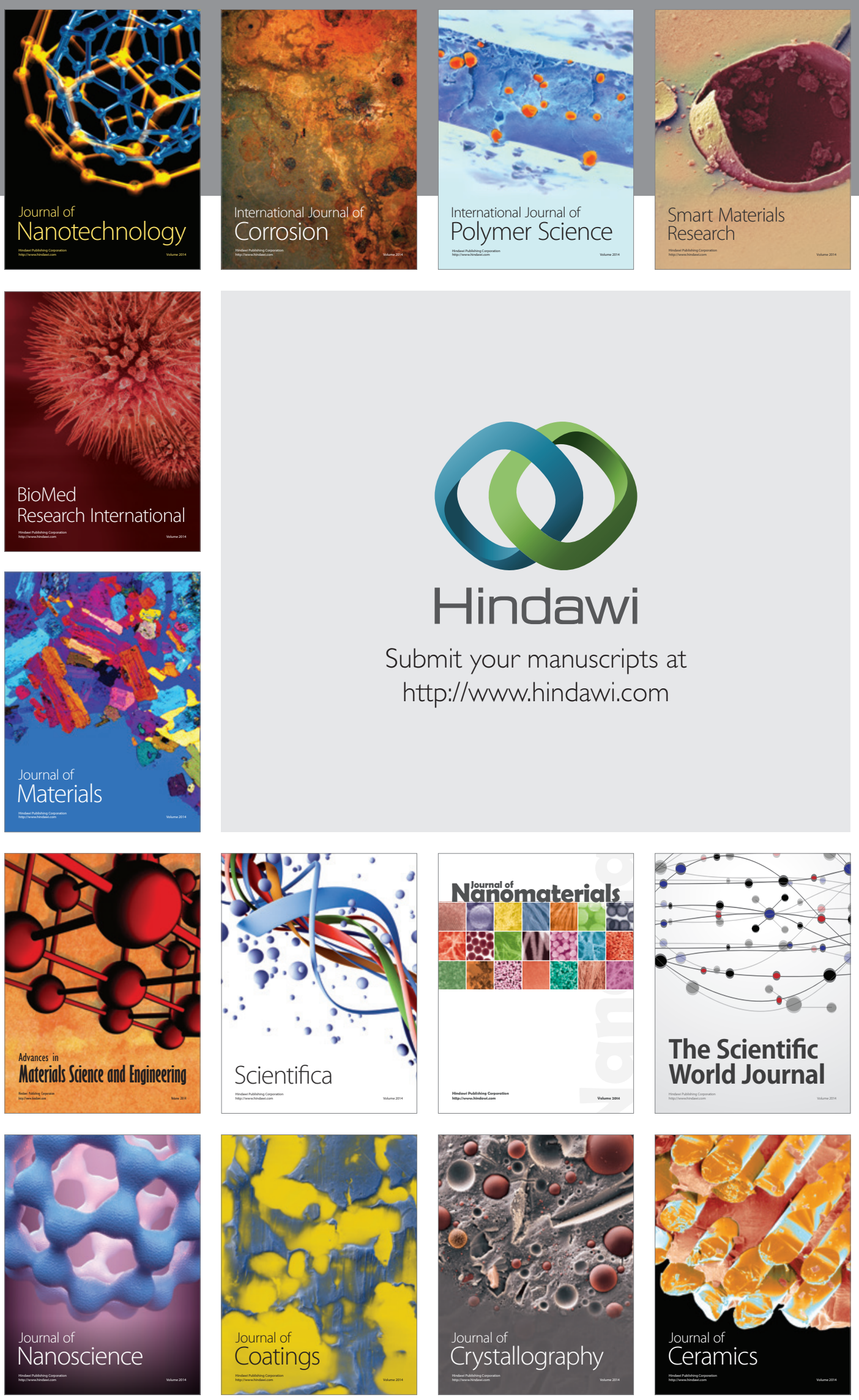

The Scientific World Journal

Submit your manuscripts at

http://www.hindawi.com

\section{World Journal}

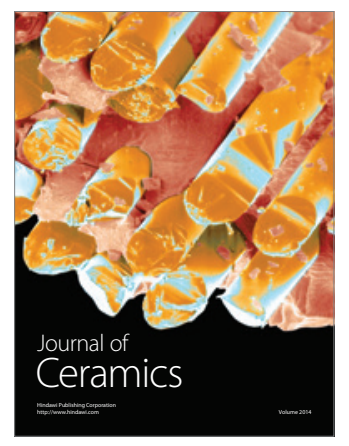

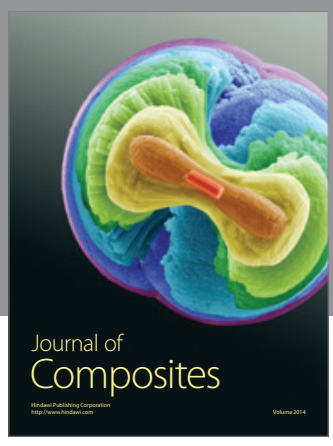
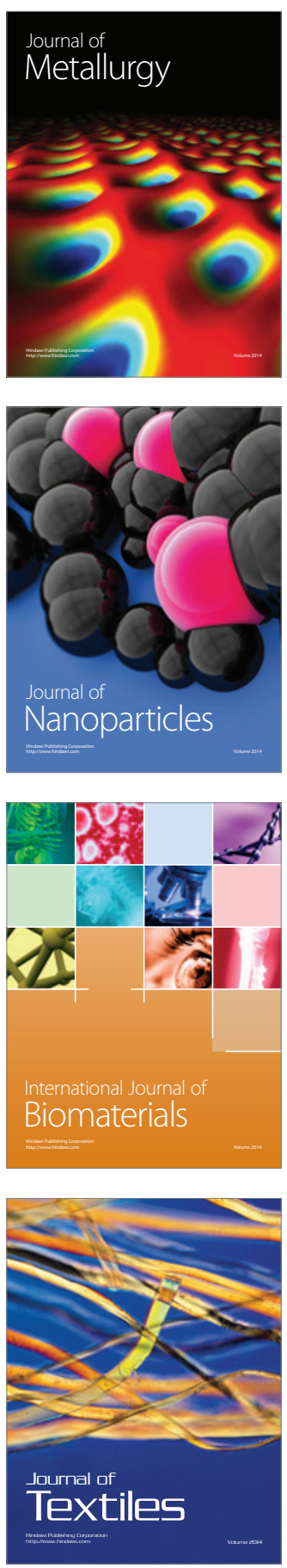